\title{
Fuel Savings and Emissions Reductions from ight Duty Fuel Cell Vehicles
}

Jason Mark, James M. Ohi, and David V. Hudson, Jr.

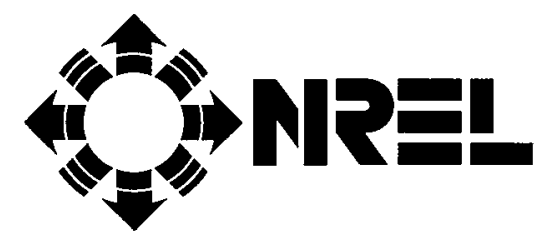

National Renewable Energy Laboratory 1617 Cole Boulevard

Golden, Colorado 80401-3393

Operated by Midwest Research Institute

for the U.S. Department of Energy

Under Contract No. DE-AC02-83CH10093 


\section{Fuel Savings and Emissions Reductions from Light Duty Fuel Cell Vehicles}

Jason Mark, James M. Ohi, and David V. Hudson, Jr.

\section{NPE}

National Renewable Energy Laboratory 1617 Cole Boulevard Golden, Colorado 80401-3393

A national laboratory of the U.S. Department of Energy Operated by Midwest Research Institute for the U.S. Department of Energy under contract No. DE-AC02-83CH10093

Prepared under Task No. AS165440

April 1994 


\section{NOTICE}

NOTICE: This report was prepared as an account of work sponsored by an agency of the United States government. Neither the United States government nor any agency thereof, nor any of their employees, makes any warranty, express or implied, or assumes any legal liability or responsibility for the accuracy, completeness, or usefulness of any information, apparatus, product, or process disclosed, or represents that its use would not infringe privately owned rights. Reference herein to any specific commercial product, process, or service by trade name, trademark, manufacturer, or otherwise does not necessarily constitute or imply its endorsement, recommendation, or favoring by the United States government or any agency thereof. The views and opinions of authors expressed herein do not necessarily state or reflect those of the United States government or any agency thereof.

Printed in the United States of America

Available from:

National Technical Information Service

U.S. Department of Commerce

5285 Port Royal Road

Springfield, VA 22161

Price: Microfiche A01

Printed Copy A04

Codes are used for pricing all publications. The code is determined by the number of pages in the publication. Information pertaining to the pricing codes can be found in the current issue of the following publications which are generally available in most libraries: Energy Research Abstracts (ERA); Government Reports Announcements and Index (GRA and I); Scientific and Technical Abstract Reports (STAR); and publication NTIS-PR-360 available from NTIS at the above address. 


\section{Preface}

This study is the first in a series of supporting analyses and assessments by the Analytic Studies Division for the Fuel Cells for Transportation Program in the U.S. Department of Energy. The goals of the supporting analyses are to (1) identify critical technical, market, and policy issues; (2) assist in overall program planning, definition, and direction; and (3) coordinate public outreach and information transfer. This report supports that agenda through assessing the potential fuel savings and emissions reductions from large-scale fuel cell vehicle (FCV) deployment and identifying the key parameters that impact the scope of those benefits. In doing so, the technical, systems, and market analyses that comprise this study provide information that can directly interface with the program's planning process. This initial study also provides input to a continuing quality metrics (QM) initiative that seeks to measure the impacts of the program on energy savings and security, environmental quality, economic competitiveness, employment, and social equity. Finally, this study and future assessments will help align the program's strategic planning such that it supports the President's Partnership for a New Generation of Vehicles that seeks to develop a production prototype with three times the fuel economy of today's vehicles.

The supporting analyses and assessments activity is an evolutionary process and, as such, the results of this study should be understood as only a piece of the final analytical picture. For example, as the following text notes, we have not characterized all of the potential benefits of fuel cell technology in transportation technologies, nor have we attempted to quantify the likely costs associated with a transition to large-scale FCV use. In addition, the study investigates the role of FCVs as a potential alternative to conventional internal combustion engine vehicles only and does not attempt to investigate competing alternatives. Future work will build on this initial study to provide additional information in many of these areas, particularly as they relate to the overall goals of the supporting analyses and assessments work.

The authors wish to thank Pandit Patil, Steven Chalk, Donna Loe, and Bob Kost of the Fuel Cells for Transportation Program for their support and guidance throughout this work. In addition, numerous analysts provided useful comments along the way, and the authors would like to thank Walt Podolski, Philip Patterson, John Maples, Jim Moore, David Chien, Mark DeLuchi, David Greene, Barry McNutt, and Lois Platte for their help in providing data and critical review.

Approved for the

NATIONAL RENEWABLE ENERGY LABORATORY

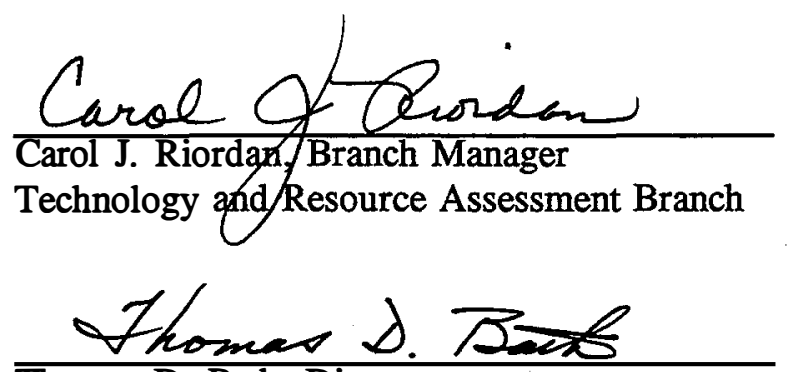

Thomas D. Bath, Director

Analytic Studies Division 


\section{Table of Contents}

page

Executive Summary $\ldots \ldots \ldots \ldots \ldots \ldots \ldots \ldots \ldots \ldots \ldots \ldots \ldots \ldots$

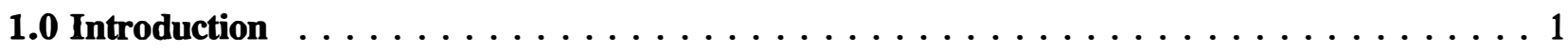

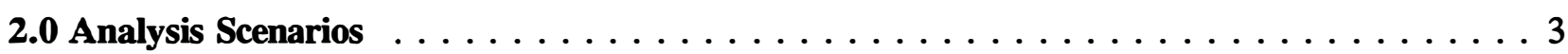

2.1 Market Segments $\ldots \ldots \ldots \ldots \ldots \ldots \ldots \ldots \ldots \ldots \ldots \ldots \ldots \ldots \ldots \ldots \ldots \ldots$

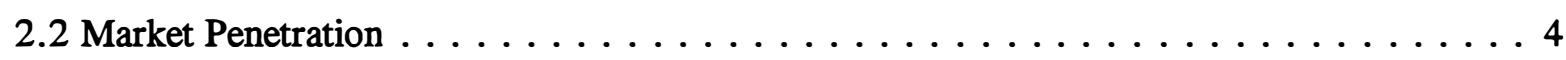

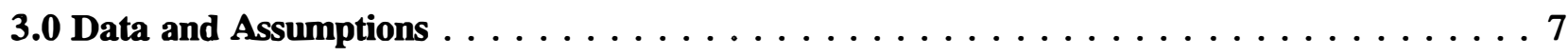

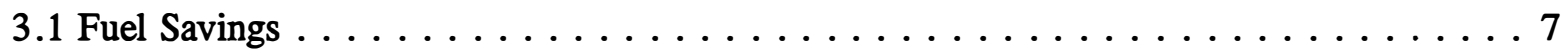

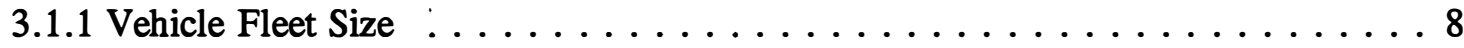

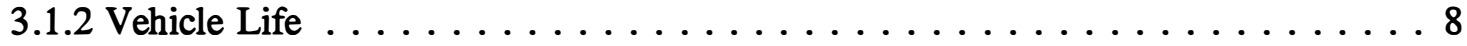

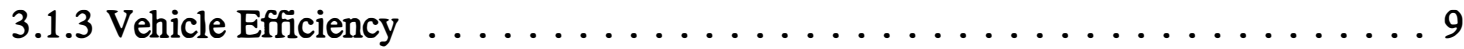

3.1.4 Fuel Costs ......................... 11

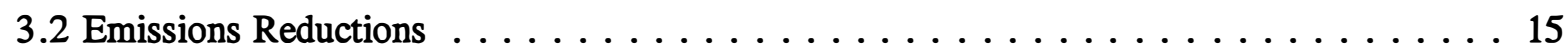

3.2 .1 Upstream Emissions . . . . . . . . . . . . . . . . . . 16

3.2.2 Conventional Vehicle Emissions . . . . . . . . . . . . . . . . 19

3.2.3 Fuel Cell Vehicle Emissions . . . . . . . . . . . . . . . 23

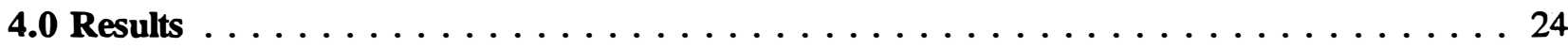

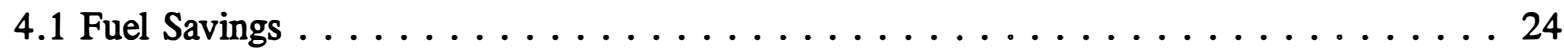

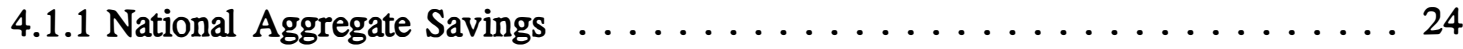

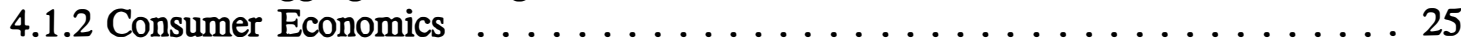

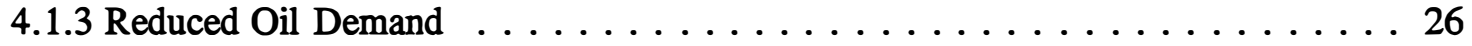

4.1.4 Parametric Studies . . . . . . . . . . . . . . . . . 27

4.2 Emissions Reductions . . . . . . . . . . . . . . . . . . . 29

4.2.1 Total Emissions Reductions .................... 31

4.2.2 Parametric Studies . . . . . . . . . . . . . . . . . 33

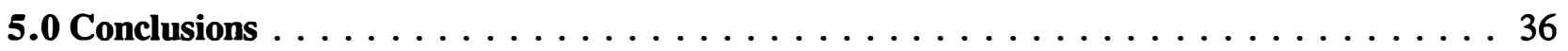

5.1 Research Needs . . . . . . . . . . . . . . . . . . . 36

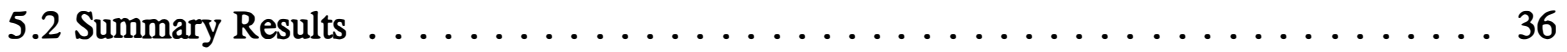

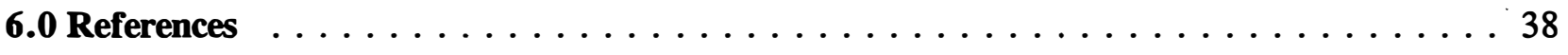

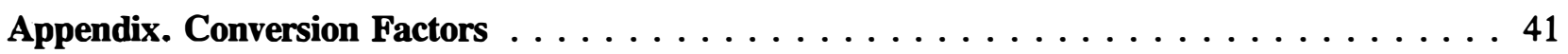




\section{List of Tables}

page

Table 1. Upstream Emissions Estimates for Various Fuel Cycles $\ldots \ldots \ldots \ldots \ldots$

Table 2. Present Value (in 1994) of Fuel Cost Savings from Light Duty

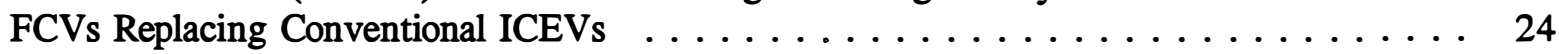

Table 3. Present Value of Fuel Cost Savings of New Fuel Cell Vehicles . . . . . . . . . . . . 26

Table 4. Cumulative Emissions Reductions from the Use of

Fuel Cell Vehicles for the Period 2010-2030 . . . . . . . . . . . . . . . . 32

Table 5. Present Value of Fuel Savings and Emissions Reductions

from the Deployment of Light Duty Fuel Cell Vehicles $\ldots \ldots \ldots \ldots$. . . . . . . 37

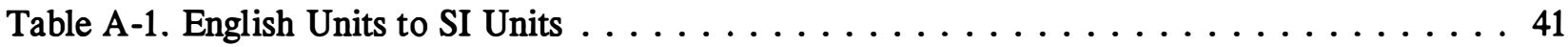

Table A-2. Conversion of Common Units $\ldots \ldots \ldots \ldots \ldots \ldots \ldots$

\section{List of Figures}

page

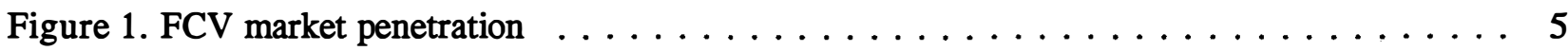

Figure 2. Projected new light duty vehicle sales $\ldots \ldots \ldots \ldots \ldots \ldots \ldots$

Figure 3. New automobile fuel economy assumptions $\ldots \ldots \ldots \ldots \ldots \ldots \ldots$

Figure 4. Assumed fuel prices for hydrogen, domestic methanol, and imported methanol from

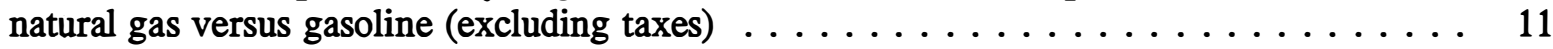

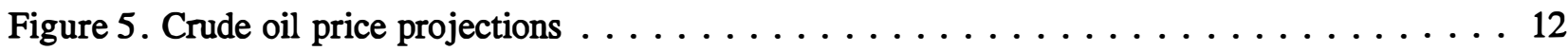

Figure 6. Reformulated gasoline fuel cycle $\ldots \ldots \ldots \ldots \ldots \ldots \ldots \ldots$

Figure 7. Methanol from natural gas fuel cycle $\ldots \ldots \ldots \ldots \ldots \ldots$

Figure 8. Hydrogen from natural gas fuel cycle $\ldots \ldots \ldots \ldots \ldots \ldots \ldots$

Figure 9. Age distribution of displaced ICEVs in select analysis years $\ldots \ldots \ldots \ldots$

Figure 10. Modeled $\mathrm{NO}_{x}$ emissions versus standards for automobiles, by vehicle age $\ldots \ldots \ldots 22$ 


\section{List of Figures (Concluded)}

page

Figure 11. Results of the parametric studies for methanol fuel cell vehicles . . . . . . . . . 28

Figure 12. Results of the parametric studies for hydrogen fuel cell vehicles . . . . . . . . . . 29

Figure 13. NMOG emissions from light duty vehicle use in $2020 \ldots \ldots \ldots$. . . . . . . . 30

Figure 14. CO emissions from light duty vehicle use in $2020 \ldots \ldots \ldots \ldots$

Figure 15. $\mathrm{NO}_{\mathrm{x}}$ emissions from light duty vehicle use in $2020 \ldots \ldots \ldots \ldots \ldots$

Figure 16. $\mathrm{CO}_{2}$ emissions from light duty vehicle use in $2020 \ldots \ldots \ldots \ldots \ldots$

Figure 17. Cumulative environmental benefits (with and without $\mathrm{CO}_{2}$ valuation) $\ldots \ldots 33$

Figure 18. Parametric studies of emissions reductions $\ldots \ldots \ldots \ldots \ldots \ldots$ 


\section{Executive Summary}

\section{S-1. Introduction}

More than one-quarter of all energy consumed in the United States is used to transport people and goods. Because the majority of this energy is consumed by vehicles using fuels derived from petroleum, the transportation sector is responsible for nearly two-thirds of U.S. oil consumption. As net imports of oil have been increasing over the past two decades and are already $46 \%$ of the total demand today (Davis and Strang 1993), ${ }^{1}$ transportation is a major source of foreign oil dependence. The transportation sector is also responsible for $70 \%$ of the nation's emissions of carbon monoxide (CO), $30 \%$ of the volatile organic compounds (VOCs), and $39 \%$ of the nitrogen oxides $\left(\mathrm{NO}_{x}\right)$ (EPA 1992), all of which are major components of air pollution. Moreover, about one-third of the total carbon released by the United States (EIA 1993) comes from transportation use, thereby making the sector a major contributor to the problem of global climate change.

Fuel cell vehicles (FCVs) have the potential to mitigate these economic and environmental concerns as a result of their high efficiency, low emissions characteristics, and ability to operate on non-petroleum fuels. This analysis characterizes the benefits of large-scale FCV deployment in the light duty vehicle (LDV) market, focusing on fuel savings and emissions reductions as two key, quantifiable benefits to the nation. Additional benefits, not studied here, might be derived from reduced pressures on trade balances from decreased oil imports, oil price reductions from lowered demand, and enhanced U.S. competitiveness from a successful domestic FCV manufacturing industry. As this study is the first in a series of supporting analyses and assessments, future work will attempt to characterize these additional potential benefits in detail. Further study will also focus on the potential costs of a transition to commercial FCV use. In particular, the infrastructure requirements of fuel production and distribution networks, vehicle manufacture, and vehicle servicing should be studied further to identify possible barriers or opportunities for FCVs.

\section{S-2. Analysis Scenarios}

Fuel cell vehicles were assumed to compete with gasoline-powered light trucks and passenger cars in the new vehicle market for replacement of retired vehicles and for growth in the total market. The analysis spans the time period 1994-2030. It assumes that FCVs operating on either methanol or hydrogen will be commercially available by $2010 .^{2}$ The initial cost of the FCV may or may not have reached parity with internal combustion engine vehicles (ICEVs) for equivalent duty at that time, and the performance of the FCV may not yet be adequate for some applications. Due to the uncertainty of such projections, this analysis does not estimate FCV purchase price directly ${ }^{3}$ but rather quantifies the purchase price premium that consumers might accept if they wish to offset any higher initial cost with lower fuel expenditures over the vehicle's lifetime. Such fuel savings may provide the added incentive needed by

1 EIA (1993) projects that net imports will be $61 \%$ of total U.S. oil supply by the year 2010 .

2 The impacts of delayed penetration are also considered in this analysis, as described below.

3 A preliminary analysis of FCV powerplant costs for a proton exchange membrane system has recently been published that lays out the key issues and makes initial cost estimates (GM/Allison 1993). 
the consumer, particularly those who accumulate substantially higher mileages than the average. ${ }^{4}$ Emission regulations, vehicle use mandates, or other considerations may provide added incentives for some buyers.

After 2010, widespread fuel availability, demonstrated vehicle reliability, and a history of reasonable maintenance costs (after an initial shake-down period) are assumed to expand the market. As shown in Figure S-1, three market penetration scenarios were assessed in detail for this analysis: a base case and high and low market penetrations. In the base case, FCV sales are assumed to increase steadily and, by 2030 , market penetration reaches $24 \%$ of new vehicle sales

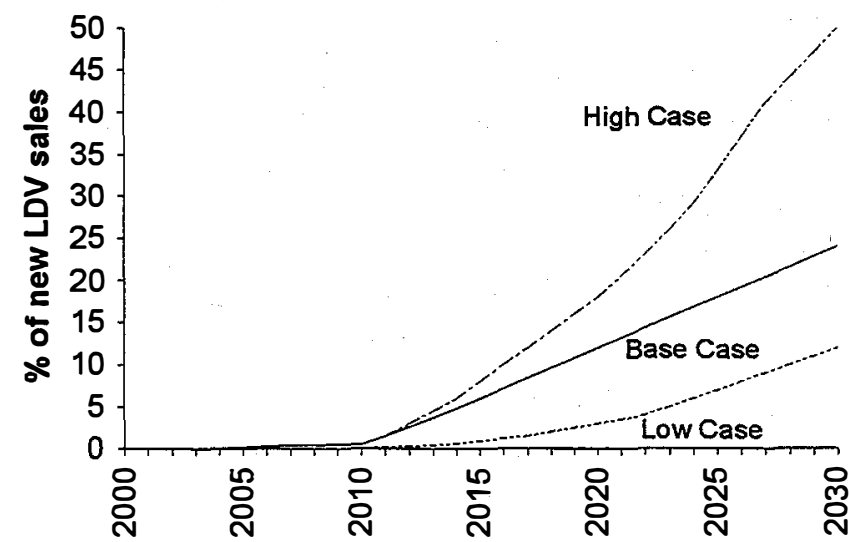

Figure S-1. FCV market penetration in each the passenger car and total light truck markets. ${ }^{5}$ The high penetration scenario assumes FCVs will capture $50 \%$ of the new car and light truck sales by 2030 . Such a penetration rate might accompany a rapid demonstration of FCV performance and reliability, equivalent or lower FCV purchase price, increased environmental pressures, legislative mandates, or sustained high oil prices. Finally, a low penetration case was also studied in which market entry was delayed 5 years and market share reached only $12 \%$ by 2030 , perhaps as a result of competition with other alternatives, failure to fully realize technical and economic goals, or unsustained emphasis on environmental issues in the transportation sector. ${ }^{6}$

\section{S-3. Fuel Savings}

We analyzed fuel savings from two perspectives in this analysis: (1) aggregate savings to the nation as a whole and (2) present value of savings to users over the life of the vehicle. These savings are based on the relative prices of the fuels used in the FCV and ICEV combined with assumptions about their relative fuel economies. In addition, we have also calculated the volume of oil displaced through the use of FCVs and the "national security" value of this reduction.

Methanol and hydrogen for the FCVs were assumed to be derived from natural gas feedstocks only, although preliminary results indicate that the potential savings associated with moving to alternative

4 In $1987,15 \%$ of light trucks were operated 30,000 miles or more (Bureau of the Census 1990).

5 In the light truck market, market penetration rates are expressed as shares of the total market, i.e., both commercial and personal vehicles; however, penetration is assumed to occur primarily in the commercial segment. Thus, although the base case assumes that $24 \%$ of all new light truck sales will be FCVs by 2030 , all of these will be in the commercial segment, and the percentage of commercial light truck sales will be higher.

6 A fourth penetration scenario was also considered in the parametric studies portion of the analysis. This scenario corresponds to estimates made by an ongoing, multitechnology strategic planning activity within the Office of Transportation Technologies (OTT). The OTT scenario assumes that FCV sales will capture $35 \%$ of the market by 2030 . 
feedstocks, such as solar energy or biomass, might be substantial. Because the price of methanol and hydrogen are projected to be higher than that of gasoline over the analysis period, ${ }^{7}$ any savings in fuel costs to users of FCVs must be derived from the higher fuel economy of the FCV.

Two levels of efficiency improvement for FCVs were investigated for this analysis to assess the impact of achieving varying degrees of technical success (see Figure S2). ${ }^{8}$ Fuel economy is expected to increase rapidly in the first 15 years of prototype testing and commercial operation as a consequence of systems optimization and improvements in catalysts, reformer

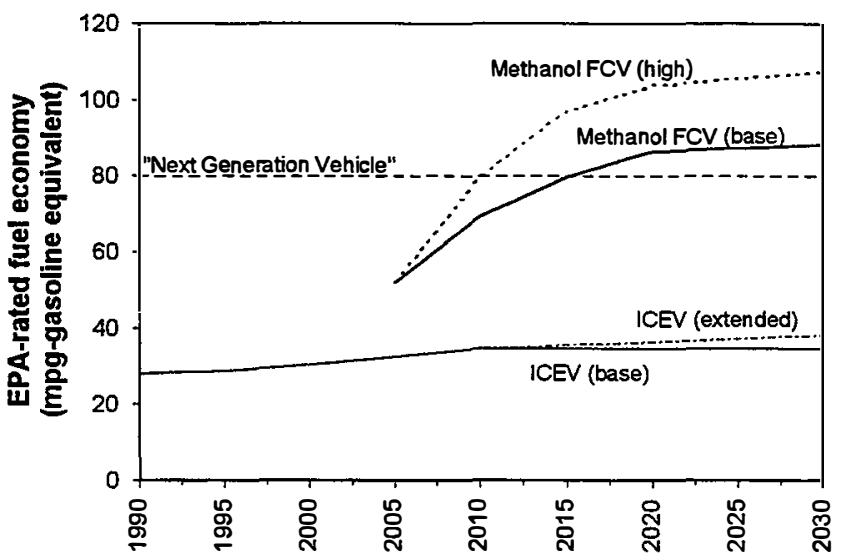

Figure S-2. New automobile fuel economy assumptions technologies, and auxiliary systems (e.g., compressors and pumps). Also, as fuel cell materials become less costly, powerplant stacks can be optimized to decrease current densities and increase overall efficiency. After the initial rapid increase, fuel economy is assumed to improve at a much slower rate through 2030 as additional optimization is achieved. In the base case, the methanol FCV improves from 1.6 times as efficient as the conventional ICEV in 2005 to 2.0 times in 2010 (69.2 mpg-gasoline equivalent for autos; $50.7 \mathrm{mpg}$-equivalent for light trucks) and 2.5 times in 2020 (86.5 mpgequivalent for autos; $63.4 \mathrm{mpg}$-equivalent for trucks). The high case follows similar trends but represents greater technical and economic success in achieving fuel economy improvements.

Also shown in Figure S-2 is the goal of the President's Partnership for a New Generation of Vehicles (PNGV), which seeks to develop a prototype vehicle that achieves an 80-mpg fuel economy by 2004-2005 (Gates 1994). The high fuel economy scenario is consistent with the goals of the PNGV initiative, as it assumes that an $80 \mathrm{mpg}$-equivalent fuel cell automobile running on methanol will be commercially available by 2010 , five years after the development of the production prototype.

Separate estimates were made of FCV performance if fueled by hydrogen stored on board the vehicle, which would increase vehicle efficiency as a result of eliminating the intermediate methanol-reforming step. An estimated $15 \%$ improvement over the methanol FCV is projected for the FCV operating directly on hydrogen, thereby enhancing the FCV's capacity to meet the goals of the PNGV initiative.

7 Although imported methanol prices are assumed to be slightly lower than future gasoline prices, the average price of methanol (which accounts for the use of some higher-priced domestic methanol) is higher than gasoline over the analysis period.

8 Figure S-2 shows fuel economy estimates for new automobiles only; we assume that fuel cell light mucks will have similar improvements relative to conventional light trucks. 
Based on the relative fuel prices and vehicle efficiency of FCVs versus ICEVs, coupled with the previously stated assumptions regarding market penetration, the deployment of methanol FCVs at the base case rates would result in a present value of $\$ 63.8$ billion in fuel savings ( $\$ 46.5$ billion for the hydrogen FCV) over the period 1994-2030 (Table S-1). As expected, fuel savings are proportional to market penetration, with substantially larger savings being achieved in the high market penetration case and much lower savings in the low penetration case. While savings on a per vehicle basis are not dramatic, the extraordinary size of the light duty vehicle market permits national aggregate savings to be very large when millions of fuel cell cars and light trucks enter the market. It should also be noted that discounting to obtain present values tends to minimize the apparent importance of the savings in the later years, even at the low $4.0 \%$ discount rate assumed (Lippiatt 1992).

\section{Table S-1. Present Value of Fuel Cost Savings of Light Duty FCVs Replacing Conventional ICEVs (billion $\$ 1991$ at $4.0 \%$ discount rate)}

\begin{tabular}{|c|c|c|c|}
\hline & \multicolumn{3}{|c|}{ Market Penetration Case } \\
\hline & $\begin{array}{l}\text { Base } \\
24 \% \text { of New } \\
\text { Sales by } 2030\end{array}$ & 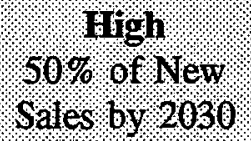 & Sales by 2030 \\
\hline 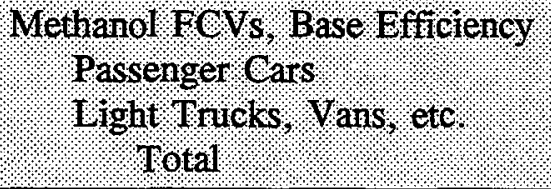 & $\frac{\$ 215}{\$ 42,3}$ & $\$ \$ \frac{\$ 33.9}{\$ 10.1 .0}$ & $\begin{array}{l}\$ 5 \% \\
\$ 11.7 \\
\$ 1 \% 6\end{array}$ \\
\hline 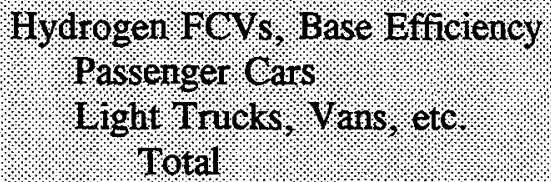 & $\frac{\$ 16.5}{\$ 30.0}$ & $\begin{array}{l}\$ 26.2 \\
\frac{847.9}{\$ 74}\end{array}$ & $\frac{\$ 5.1}{\$ 10.4}$ \\
\hline
\end{tabular}

\section{S-4. Consumer Economics}

The large savings in fuel expenditures projected in this study for light duty FCVs should make the FCV more attractive versus the conventional gasoline light duty ICEVs. If all other operating characteristics of the FCV (such as range, comfort, reliability, maintenance and insurance costs, taxes, and safety) are equal or equivalent to those of the gasoline ICEV, the fuel savings would permit a premium to be paid for the FCV. One method of estimating that premium as viewed by consumers is to discount the future fuel savings on a vehicle to their present value at the time of purchase. For such purposes, a $10 \%$ real discount rate is approximately equal to a credit card's variable interest rate for consumers or a business' minimum acceptable rate of return on new projects. A $15 \%$ real discount rate would include an additional "risk" factor to compensate for the uncertainties of the future savings. The results of the consumer-based analysis suggest that if a consumer is seeking to offset any initial premium in purchase price with lowered operating costs over the life of the vehicle, $\$ 1,500-\$ 2,500$ might be the acceptable limit for passenger cars under the base case assumptions. Commercial light trucks, because they travel 
more miles per year and because the ICEV equivalent has a higher fuel consumption rate, might permit premiums of $\$ 4,500-\$ 6,500$.

\section{S-5. Oil Reductions}

FCVs will also permit a shift from petroleum-based fuels and reduce demand for crude oil. In the base penetration case, annual oil demand reductions would reach 228 million barrels by 2020 and 876 million barrels in 2030, or a cumulative total of 6.5 billion barrels from 2000 through 2030. Applying a value of $\$ 4 /$ barrel to represent the value of oil reduction to national security, ${ }^{9} \$ 7.5$ billion might be saved over the analysis period (in present value terms) if all of the reductions were of imported oil. If only half of the oil demand reduction were of imported oil, the total security benefits would be roughly $\$ 3.7$ billion.

\section{S-6. Emissions Reductions}

The environmental analysis focuses on emissions of interest for local air quality-namely the regulated pollutants non-methane organic gases (NMOG), $\mathrm{NO}_{x}$, and $\mathrm{CO}$-as well as carbon dioxide $\left(\mathrm{CO}_{2}\right)$ because of its important role in global climate change. Traditional environmental analyses of the transportation sector have focused exclusively on emissions from the vehicle tailpipe. While this analysis confirms that these "tailpipe" emissions are in fact a primary component of transportation emissions, it also shows that the air emissions associated with producing and distributing the fuel to the end user are not small.

For the base case, we have assumed that future vehicles will comply with the Tier I standards of the 1990 Clean Air Act Amendments (CAAA) ${ }^{10}$ and that a low-volatility summertime reformulated gasoline will be used on a national basis. We have also assumed that all regions will have adopted an enhanced inspection/maintenance (I/M) program, an anti-tampering program, and on-board and pump-side evaporative emissions controls by 2010 . In addition to the federal standards, we construct an alternative case to use as a lower bound in which all states adopt the California Low Emissions Vehicle (LEV) Program.

Vehicular emissions for the hydrogen FCV are zero, since the only by-products of vehicle use are small amounts of heat and water. Vehicular emissions for FCVs operating on methanol and using an on-board reformer are very low; however, the on-board storage of methanol will result in small amounts of evaporative NMOG emissions, and the operation of the on-board reformer is expected to release limited quantities of $\mathrm{CO}, \mathrm{NO}_{\mathrm{x}}$, and NMOG.

Based on the differences in grams/mile emissions between ICEVs and FCVs combined with the assumed FCV penetration rates, total quantities of avoided emissions are calculated to demonstrate the overall environmental benefits of FCVs. As Table S-2 indicates, sizeable reductions of key pollutants are available from the use of FCVs. Depending on the pollutant and technology characterized, 70\%-99\% of

9 National security impacts from oil imports include the threat of supply disruption or manipulation as well as military expenditures to maintain access to Persian Gulf oil. A wide range of estimates have been proposed in the literature (CRS 1992, EMF 1982); this value is derived from the aforementioned OT T strategic planning activity.

10 However, as our analysis indicates, actual in-use emissions are typically much higher than the mandated certification standards as a result of deterioration, poor maintenance, and other factors that affect emissions characteristics. 
the total fuel cycle emissions associated with ICEVs can be avoided by the use of FCVs over the period 2010-2030.

Table S-2. Cumulative Emissions Reductions from the Use of Fuel Cell Vehicles for the Period 2010-2030

\begin{tabular}{|c|c|c|c|c|}
\hline & \multicolumn{2}{|c|}{ Avioried Emissions } & \multicolumn{2}{|c|}{ Einissiens Rediletionis? } \\
\hline & Methanol frev. & Hydrogen FCV? & Methanot frel. & Hydrogen FCY \\
\hline $\mathrm{NMOO}$ & 122 & 3.5. & $86 \%$ & $95 \%$ \\
\hline $\mathrm{NO}_{*}$ & 53 & 58 & $73 \%$ & $8 . \%$ \\
\hline Co. & 36.9 & 37.0 & $99 \%$. & $99 \%$ \\
\hline co. & 2,298 & 2,329 & $70 \%$ & $7 \%$ \\
\hline
\end{tabular}

To place the economic and environmental analyses on an equal footing, we calculated the economic value of the displaced emissions by using estimates of criteria pollutant $\left(\mathrm{NMOG}, \mathrm{CO}\right.$, and $\mathrm{NO}_{\boldsymbol{x}}$ ) values that represent the avoided cost implied by the 1990 CAAA (DOE 1990). Although the role that carbon emissions play in global climate change remains controversial, we have also estimated a monetary value for $\mathrm{CO}_{2}$ reductions. The results of sensitivity studies demonstrate that the cumulative benefits from reducing emissions increase substantially when a monetary value is placed on $\mathrm{CO}_{2}$ reductions. As in the case of the fuel savings analysis, benefits accrued in the future are scaled back to present value using a 4.0\% discount rate (Lippiatt 1992). The cumulative benefits accrued by reducing emissions through 2030 are estimated at $\$ 10.8$ billion for the methanol FCV ( $\$ 22.1$ billion if $\mathrm{CO}_{2}$ is valued) and $\$ 11.5$ billion for the hydrogen FCV ( $\$ 23.0$ billion with $\mathrm{CO}_{2}$ valuation).

\section{S-7. Conclusions}

The potential benefits from the deployment of FCVs, measured in terms of reduced consumer outlays for motor fuel and the value of reduced air emissions, are substantial. As Table S-3 indicates, these benefits could total $\$ 74.6$ billion by the year 2030 for the methanol FCV and $\$ 58.0$ billion for the hydrogen FCV under the penetration scenarios described in this analysis. 
Table S-3. Present Value ${ }^{a}$ of Fuel Savings and Emissions Reductions from the Deployment of Light Duty Fuel Cell Vehicles

(billion \$1991)

\begin{tabular}{|c|c|c|c|c|c|c|}
\hline & \multicolumn{2}{|c|}{ Base Penetration } & \multicolumn{2}{|c|}{ High penetration } & \multicolumn{2}{|c|}{ 180w Penetration } \\
\hline & Methonol: & risdrogen & Hethanol: & 14y6rogen & Mrethonot: & Hodrogen. \\
\hline giel savings: & 63.8 & 46.5 & $101 \%$ & $(74.1 \%$ & $17 \%$ & 15.5 \\
\hline Emissions Reductions'? & 10.8 & 105 & 17.1 & 18.3 & 3.0 & 32. \\
\hline 1014. & 746 & 580 & 18.1 & 92.4 & 206 & 187 \\
\hline
\end{tabular}

- Cumulative benefits over the period 1994-2030, discounted at a real rate of $4.0 \%$.

- Excludes valuation of $\mathrm{CO}_{2}$ reductions.

Our results show that benefits from the deployment of FCVs increase sharply over time, thereby underscoring the importance of a long-term perspective in assessing fuel cells and other advanced transportation technologies. In addition, given the uncertainties of vehicle design, fuel supply costs, and future emissions standards, selecting a best vehicle/fuel combination based on the fuel savings and emissions reductions characterized in this study would be premature at this point. This analysis clearly demonstrates that the high efficiency and low emissions characteristics of fuel cell vehicles (regardless of the specific configuration), combined with their ability to operate on non-petroleum fuels, offers large potential benefits to the nation.

In addition to the results presented here, our analysis has identified several areas where additional study can help refine the current work and provide a more complete accounting of the costs and benefits of a transition to FCVs. Some areas for further study include FCV costs, additional market characterization, the cost of fuels derived from renewable feedstocks, and infrastructure requirements (fueling, vehicle production, and maintenance). 


\subsection{Introduction}

The transportation sector presently accounts for more than one-quarter of the total primary energy demand in the United States, a situation that is expected to continue through the beginning of the next century (EIA 1993). More importantly, transportation is responsible for nearly two-thirds of the U.S. oil consumption. As net imports of oil have been increasing over the past two decades and are already $46 \%$ of the total demand today (Davis and Strang 1993), ${ }^{1}$ transportation energy use is a major source of foreign oil dependence.

The transportation sector also accounts for a large portion of the environmental impacts associated with energy use. Transportation technologies are responsible for approximately $70 \%$ of the nation's emissions of carbon monoxide, $30 \%$ of the volatile organic compounds, and $39 \%$ of the nitrogen oxides (EPA 1992), all of which are major components of air pollution. Moreover, transportation energy use is responsible for about one-third of the total carbon emitted by the United States (EIA 1993) and is therefore a major contributor to the problem of global climate change.

Because fuel cell vehicles are highly efficient, have inherently low emissions, and can operate on nonpetroleum fuels, they can play an important role in mitigating the economic and environmental concerns associated with energy use in the transportation sector. Commercialization of fuel cells for transportation in the United States can have the following benefits:

(1) The substantial increases in efficiency projected for FCVs will bring sizeable savings to consumers in the form of reduced outlays for fuel.

(2) The low emissions characteristics of FCVs will permit consumers to maintain a high level of personal mobility while simultaneously reducing the overall environmental impact of such travel.

(3) A shift away from non-petroleum fuels will reduce dependence upon foreign oil, thereby reducing pressures on trade balances and increasing economic, political, and military security.

(4) Reduced demand for oil may also lower world oil prices and, as a result, provide benefits that extend beyond the transportation sector to the entire domestic economy as well as that of other nations.

(5) A successful domestic FCV manufacturing industry can enhance the competitiveness of the domestic automotive industry, generate jobs for the nation, and strengthen the position of the United States in international markets.

This analysis focuses on the benefits from fuel savings and emissions reductions that can be accrued through the large-scale deployment of FCVs. Estimates of the lowered demand for oil are also made, along with a measure of the national security benefits associated with such a reduction. Additional benefits, not characterized in this report, might be derived from changes in employment, trade balances, international competitiveness, and oil and gas price shifts, as indicated above.

1

EIA (1993) projects that net imports will be $61 \%$ of total U.S. oil supply by the year 2010 . 
As this study is the first in a series of supporting analyses and assessments (see Preface), future work will attempt to characterize these potential benefits in detail. Additional study will also focus on the potential costs of a transition to commercial FCV use. In particular, the infrastructure requirements of fuel production and distribution, vehicle manufacture, and vehicle servicing should be studied further to identify potential barriers or opportunities for FCVs. Section 5.1 outlines several directions for future research that can facilitate an improved understanding of FCV issues.

The study described here estimates benefits for one of the highest priority areas of the energy sector; however, the benefits of fuel cell technologies may extend well beyond the automotive and light truck segment to heavy trucking, rail, electric power generation and distribution, and on-site cogeneration of power. Research into these potential markets and the resulting energy, economic, and environmental benefits is continuing. In particular, the program is currently supporting an effort to characterize the technical feasibility and potential benefits of fuel cell use in the heavy duty vehicle market. Heavy, overthe-road combination trucks appear to be a particularly promising market as a result of high annual mileage accumulations, rapid turnover rates, high emissions rates, and the high fuel consumption of conventional diesel power trucks.

The following sections describe in detail the data, assumptions, and results of this study. Section 2.0 (Analysis Scenarios) identifies the market penetration scenarios assumed for the analysis. Section 3.0 (Data and Assumptions) details the inputs to the fuel savings and emissions reductions calculations. Results of the analysis are shown in Section 4.0 (Results), and the outputs of a series of parametric studies (sensitivity analyses) are reported. Finally, Section 5.0 (Conclusions) coordinates the results of the work and identifies areas where additional study is needed. 


\subsection{Analysis Scenarios}

To demonstrate the potential benefits of FCVs, three technology/fuel combinations were characterized: (1) conventional internal combustion engine vehicles operating on reformulated gasoline ${ }^{2}$ - the benchmark technology, (2) FCVs operating on methanol that have an on-board reformer for converting methanol to hydrogen for use in the fuel cell, and (3) FCVs with on-board hydrogen storage capabilities. Both of the FCVs are assumed to use the proton exchange membrane (PEM) fuel cell technology, which appears to be particularly promising for the mid-term as a result of high power density and potential low cost. ${ }^{3}$

This analysis focuses exclusively on scenarios in which FCVs displace conventional ICEVs operating on gasoline. Other alternative vehicles-battery-powered electric vehicles, hybrid/electric vehicles, or ICEVs fueled by compressed natural gas, alcohols, or liquid petroleum gas-may also be capable of making significant contributions, possibly in competition with FCVs. Such comparisons are being made elsewhere in the Office of Transportation Technologies and have not been explicitly considered here. ${ }^{4}$

\subsection{Market Segments}

Two market segments were analyzed: passenger cars and commercial light trucks. Passenger cars (defined narrowly to exclude station wagons, vans, jeeps, and other utility vehicles used for personal transportation) represent about two-thirds of the light duty vehicle fleet and are driven an average of about 10,000 miles per year (16,090 km/yr) (Davis and Strang 1993). ${ }^{5}$ Most of the passenger cars are owned by individuals and are used for personal, rather than business, travel. They were analyzed separately from the balance of the vehicles because passenger cars are generally lighter and have higher fuel economies than the other vehicles.

Light trucks comprise the balance of the light duty vehicle fleet and are defined here (and in most official statistical sources) as pickup trucks, vans, utility vehicles (e.g., jeeps), panel trucks, station wagons, and other trucks of less than 10,000 pounds $(4540 \mathrm{~kg}$ ) weight. Light truck sales have been growing more than twice as fast as passenger cars since 1970 and are expected to continue to exceed the passenger car rates. ${ }^{6}$ By 2030, the total fuel demand of the light truck segment is projected to equal that of the passenger cars.

2 Diesel-fueled vehicles account for less than $1 \%$ of the nation's light duty vehicle stock or fleet and are not studied in this analysis.

3 A brief overview of fuel cell technologies and their application to transportation systems can be found in OTT (1994).

4 An ongoing analysis within the Office of Transportation Technologies, U.S. Department of Energy, is characterizing multiple alternative technologies as part of a strategic planning exercise. The assumptions and methods in this analysis are roughly consistent with this activity; differences, when they do exist, are explicitly noted in the text.

5 In compliance with federal law, all Department of Energy documents released after October 1, 1992, must incorporate the use of metric (SI) units (DOE Order 5900.2). Recognizing the dominance of English units in most U.S. transportation standards and measures, the traditional units are the primary measurement provided in the text, with SI units provided in parentheses. A conversion table is provided in Appendix A.

6 The rapid growth had been concentrated in the pickup truck segment, but recent growth of the personal van segment has accelerated. The projections used in this study assume that passenger car sales continue to grow at the 1970-1990 rate and light trucks supply the balance. Continued improvement in meeting personal, especially family, transportation needs is assumed in the van and utility vehicle (jeep) segments. 
Two-thirds of the light trucks are used primarily for personal transportation; the balance are used for a variety of commercial purposes, including freight and services. Based on the available data, commercial light duty rucks appear to be driven an average of 15,000 miles per year $(24,135 \mathrm{~km} / \mathrm{yr})$, while those used for personal transportation are driven about 10,000 miles per year $(16,090 \mathrm{~km} / \mathrm{yr}$ ) (Bureau of Census 1990). As a result, the commercial segment appears to be the most atractive market for FCVs in the light truck sector, not only because these vehicles are used more intensively, but also because half of these vehicles are utilized in fleets. ${ }^{7}$ Fleet operators, particularly those operating from a central operations/maintenance facility, may be better able to take advantage of the economics or environmental benefits of FCVs, particularly if special fuels or maintenance are required during the early stages of market penetration. In the pre-commercialization product development period, FCVs (as well as other new technologies) will require extensive tests in government and/or private fleets. Incentives are likely to be required; such incentives may be financial or as the result of environmental regulation or legislation. Although fleets may provide a pre-commercial testing ground, our analysis assumes FCVs penetrate the entire commercial light truck market, including fleet and non-fleet vehicles.

\subsection{Market Penetration}

Fuel cell vehicles were assumed to compete with gasoline-powered light trucks and passenger cars in the new vehicle market for normal replacement of retired vehicles and for growth in the total market. Although not considered in this analysis, additional sales might occur if FCVs were priced attractively enough to induce early retirement of gasoline vehicles as a result of fuel cost savings and/or emissions reductions.

The analysis spans the time period 1994-2030 and assumes that FCV technologies will be commercially available by $2010 .^{8}$ By that date, there is assumed to be sufficient demand for FCVs to support one or more production lines. The initial cost of the FCV may or may not have reached parity with ICEVs for equivalent duty at that time, and the performance of the FCV may not yet be adequate for some applications. While this analysis does not directly estimate FCV purchase price, ${ }^{9}$ Section 4.1 .2 quantifies the premium in purchase price that consumers might accept if they wish to offset a higher initial cost with lower fuel expenditures over the vehicle's lifetime. Such fuel cost savings may provide the added incentive needed by the consumer, particularly those who accumulate substantially higher mileage than the average. ${ }^{10}$ Emission regulations, vehicle use mandates, or other considerations may provide added incentives for some buyers. The range of body types and sizes would obviously be limited in the early years of commercial use, and fuel availability may restrict the geographic scope of the market.

7 The benefits of FCV use in the personal light duty truck sector would, on average, be two-thirds that of commercial light duty trucks. However, more than $10 \%$ of light trucks used for personal transportation were driven more than 20,000 miles in 1987 (Bureau of the Census 1990) and the incentives as well as benefits would be correspondingly larger for such users.

8

The impacts of delayed penetration are considered in Section 4.1.4.

9 A preliminary analysis of FCV powerplant costs for a PEM system has recently been published that lays out the key issues and makes preliminary cost estimates (GM/Allison 1993).

10

In $1987,15 \%$ of light trucks were operated 30,000 miles or more (Bureau of the Census 1990). 
After 2010, widespread fuel availability, demonstrated vehicle reliability, the availability of a wider range of body types and sizes, and a history of reasonable maintenance costs (after an initial shakedown period), are assumed to expand the market. The vehicle and parts manufacturers and the fuel and maintenance service industries are assumed to gradually shift facilities and output as needed. The rate of expansion of the market is assumed to be slower than might be assumed if consumers could be quickly assured of the performance, costs, reliability, and adequacy of fuels and service for the FCV. In addition, if other vehicle technologies are competing successfully with FCVs, the market expansion for each would be constrained. However, FCV development can also build upon experience gained in developing other electric vehicle technologies, including battery powered and hybrid electric vehicles. Sufficient overlap exists between these three technologies to permit the transfer of battery, controller, motor, braking, and other electric systems technologies.

Environmental issues, major oil price increases, or limitations of oil availability would be possible causes of a more rapid penetration of alternative fuel vehicles. Fuel savings alone, while significant, are not of overwhelming economic importance and are unlikely to drive a rapid penetration of FCVs in the market; the light duty vehicle market is very sensitive to reliability and predictability of vehicles, as vehicles are a crucial element of daily life and activity for nearly all users. Other factors may also contribute to FCV market success. For example, maintenance might ultimately be less costly for the FCV than its ICEV counterpart because of fewer moving parts and the lack of a high-stress combustion process.

Three market penetration scenarios were assessed in detail for this analysis, a base case and high and low market penetrations (see Figure 1). In the base case, large-scale commercial production of fuel cell vehicles was assumed to commence in 2010 following a 10year period of small-scale production and demonstration use. FCV sales are assumed to increase steadily and, by 2030, market penetration reaches $24 \%$ of new vehicle sales in each the passenger car and total light truck markets. ${ }^{11}$ The high penetration scenario assumes FCVs will capture $50 \%$ of the new car and light truck sales by 2030 . Such a penetration rate might accompany a rapid demonstration of FCV performance and reliability, equivalent or lower FCV purchase

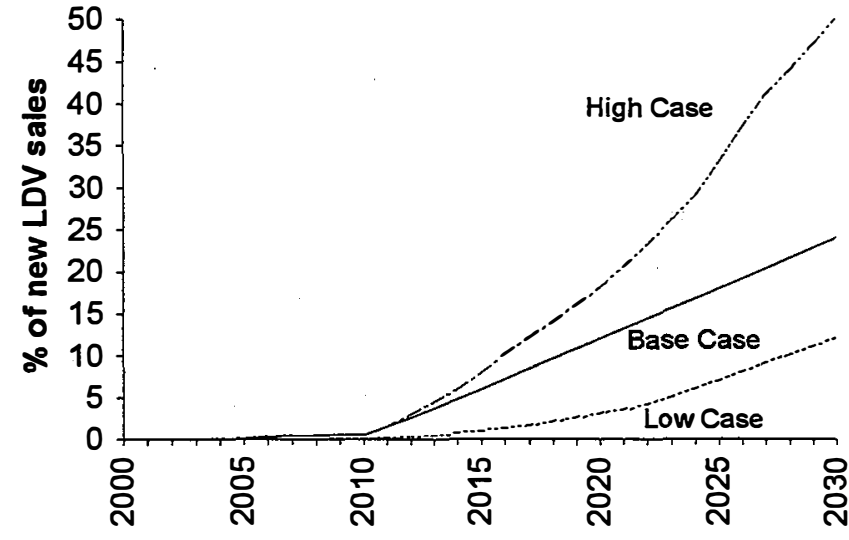

Figure 1. FCV market penetration price, increased environmental pressures, legislative mandates, or sustained high oil

\footnotetext{
11 In the light truck market, market penetration rates are expressed as shares of the total market, i.e., both commercial and personal vehicles; however, penetration is assumed to occur primarily in the commercial segment. Thus, although the base case assumes that $24 \%$ of all new light truck sales will be FCVs by 2030 , all of these will be in the commercial segment, and the percentage of commercial light truck sales will be higher. For example, the high penetration case, in which FCVs account for $50 \%$ of the total light truck market by 2030 , assumes that FCVs will capture $100 \%$ of the commercial light truck market by that year.
} 
prices. Finally, a low penetration case was also studied in which market enry was delayed 5 years and market share reached only $12 \%$ by 2030 , perhaps as a result of competition with other alternatives, failure to fully realize technical and economic goals, or unsustained emphasis on environmental issues in the transportation sector. ${ }^{12}$

The market penetration studies are based on the share of new vehicle sales, rather than vehicles in use or annual miles traveled. Consequently, given the 13- and 15-year lifetimes of these vehicles, it will take several decades for the full impact of a new technology to be realized, either in economic terms by the consumer or in environmental terms by the nation as a whole, at the rates of market penetration assumed herein. If $100 \%$ penetration of new vehicle sales were achieved in 2020 , full benefits would not be achieved until after 2035, unless early replacement of vehicles were mandatory or economically imperative. ${ }^{13}$ All alternative vehicle technologies, not just FCVs, would have similar delays in their aggregate impact, while alternative fuels for existing vehicles would have a more rapid impact if the fuel supplies and infrastructure could be implemented rapidly. The market penetration rates used in this study are assumed to be slow enough in the early years to permit automobile manufacturers to develop FCV production lines at a reasonable rate; however, further study of this issue is recommended in Section 5.1. The fuel supply outlook also requires additional study (particularly in the case of hydrogen), although the rates of FCV introduction are assumed to permit adequate supply infrastructure to be developed to meet this demand.

The analyses that follow have been based on the average passenger car and the average commercial light truck; however, greater incentives exist for users of high-mileage vehicles to buy a new type of vehicle that is more efficient. The Truck Inventory and Use Survey (TIUS) of the 1987 Census of Transportation indicated that nearly $30 \%$ of the commercial light trucks were reported to have exceeded 20,000 miles $(32,180 \mathrm{~km})$ use in 1987 (Bureau of the Census 1990). Moreover, many such vehicles are operated in fleets, which would allow any special fueling and maintenance requirements to be more readily met than in the case of individual ownership. Similarly, many passenger cars are operated substantially greater distances per year than the average; many of these vehicles are also in fleet use. The average savings per vehicle derived in this analysis can be extrapolated linearly to derive the benefits in the case of highermileage vehicles. It is possible that the first FCVs sold will be used in above-average mileage applications; thus, the potential benefits of a fuel cell vehicle program of the size indicated by any of the cases presented in this analysis may well be greater than quantified here.

Moreover, we did not study benefits or incentives for FCVs in states or regions where mileage traveled might differ from the national average or locations in which the benefits of an emissions reduction would exceed the average (e.g., air quality non-attainment areas). Because regulatory or incentive programs designed to stimulate the sale and use of FCVs are more likely in areas where greater-than-average benefits may be derived, the estimates made in this report would tend to understate the potential benefits and overstate the economic obstacles in those areas.

\footnotetext{
12 A fourth penetration scenario is considered in the parametric studies (Sections 4.1.4 and 4.2.2) corresponding to estimates made by the aforementioned Office of Transportation Technologies (OTT) strategic planning activity. The OTT scenario assumes that FCV sales will capture $35 \%$ of the market by 2030 .

13 The 13- and 15-year lifetimes are averages (Miaou 1990); some low-utilization vehicles might remain in the fleet for 25 or more years after manufacture, as is now the case.
} 


\subsection{Data and Assumptions}

Because the Fuel Cells for Transportation Program is a federal research and development (R\&D) program, this analysis sought to use data and assumptions that are consistent with other national-level, federalgovernment-oriented analyses. For example, where possible we have used projections made by the U.S. Energy Information Administration (EIA) for future transportation sector characteristics. The analysis also seeks to comport with the basic framework of ongoing analyses by the Office of Transportation Technologies, such as its strategic planning activities. An overriding force behind our choice of data and assumptions, then, is an interest in maintaining general consistency with other analyses being conducted by the Department of Energy such that the results of this work can be directly useful to the department's analytical agenda.

Because of the inherent uncertainty and variability associated with the evolution of the fuel cell technology and the projections made for the transportation sector as a whole, a series of parametric studies were conducted as a major component of the analysis. The goals of these studies are two-fold: (1) to encompass alternative projections of economic factors and future technical success and (2) to assess the importance of key parameters of interest to the program and identify their role in achieving large overall benefits. While the first goal is a necessary component of any study involving future estimates, the second is of much greater importance from a methodological perspective. Parametric studies help the program understand the importance of meeting specified technological goals or how changes in the economic or policy environment can affect the potential benefits of their technologies. For example, we have considered the impact of achieving a very high vehicle efficiency and have estimated the associated benefits versus a case in which vehicle efficiency improvements are more moderate. This provides the program with information to assess the incremental benefits that may be achieved through increased R\&D investments focused on improving vehicle efficiency. In addition, we have considered changes in exogenous parameters, such as world oil prices or conventional vehicle emissions standards, and studied their impact on the overall benefits of the program.

\subsection{Fuel Savings}

The analysis of fuel cost savings considers two different perspectives: (1) aggregate savings to the nation as a whole and (2) present value of savings to users (business or personal) over the life of the vehicle. These savings are based on the relative prices of the fuels used in the FCV and ICEV coupled with assumptions about the respective vehicle fuel efficiencies: As an additional component of the fuel savings analysis, we have also calculated the volume of oil displaced through the use of FCVs and the "security value" of this reduction.

We studied the sensitivity of the results to variations in several key assumptions: market penetration (discussed previously), vehicle efficiency, crude oil prices, the cost/price of methanol, and the prices of alternative sources (non-natural gas) of methanol and hydrogen. The analysis generates a full range of estimates, reported in Section 4.1.4, that provide insight into the importance of these major variables.

The time period of the analysis is 1994-2030. The 1993 Annual Energy Outlook (AEO93) published by the Energy Information Administration (EIA 1993) provides a framework of consistent estimates for 
vehicle travel, population, and efficiency, and conventional fuel prices through $2010 .^{14}$ Those estimates were extended to 2030, generally at rates similar to those in the EIA projections for the period 1990 2010. The analysis of fuel cell vehicles was extended to 2030 because the fuel cell vehicle technologies are not expected to be developed and demonstrated sufficiently to permit the start of mass production (100,000-300,000 units per year) until 2010, and the potential benefits of FCVs will not be fully apparent until the FCVs are able to attain large market shares. A wide range of alternative parametric studies have also been undertaken to provide an indication of the sensitivity of results to the projections of key variables in the base case.

The basic assumptions made in the study and the sources of data used in implementing those assumptions follow, including a description of the assumed vehicle fleet size, vehicle life, vehicle efficiency, and fuel costs.

\subsubsection{Vehicle Fleet Size}

The nation's fleet of light duty vehicles is projected by EIA to grow from 182 million in 1994 to 239 million in 2010 (EIA 1993), indicating that the growth in new vehicle sales will continue to outstrip the rate of vehicle retirements for that period. Assuming continued growth of vehicle fleets thereafter at similar rates, the light duty segment of the market would reach 330 million vehicles in 2030 . Light truck registrations have been growing more rapidly than passenger cars during the past two decades and are projected by EIA to continue to do so in the future, although at a slower rate. The passenger car fleet is projected to grow at an annual rate of $0.9 \%$ (EIA 1993), and the same rate was assumed thereafter. Commercial light truck sales are assumed to grow at a $1.9 \%$ annual rate, the same as for total freight trucks. While total (commercial and personal)

light truck sales grew at an annual rate of $9.0 \%$ in the 1980 s, EIA projects that these will fall to $4.0 \%$ by 2010 , and a continued decline in sales rates is assumed through 2030. New vehicle sales estimates, based on (EIA 1993) and the previously stated assumptions, are shown in Figure 2 for the light duty market.

\subsubsection{Vehicle Life}

The average expected life of passenger cars is about 13 years, and that of light trucks is 15 years (Miaou 1990). Given an average annual mileage of 10,000 miles $(16,000 \mathrm{~km})$ for passenger cars and personal light trucks and 15,000 miles $(24,000 \mathrm{~km})$ for commercial light trucks, this results in a vehicle life of

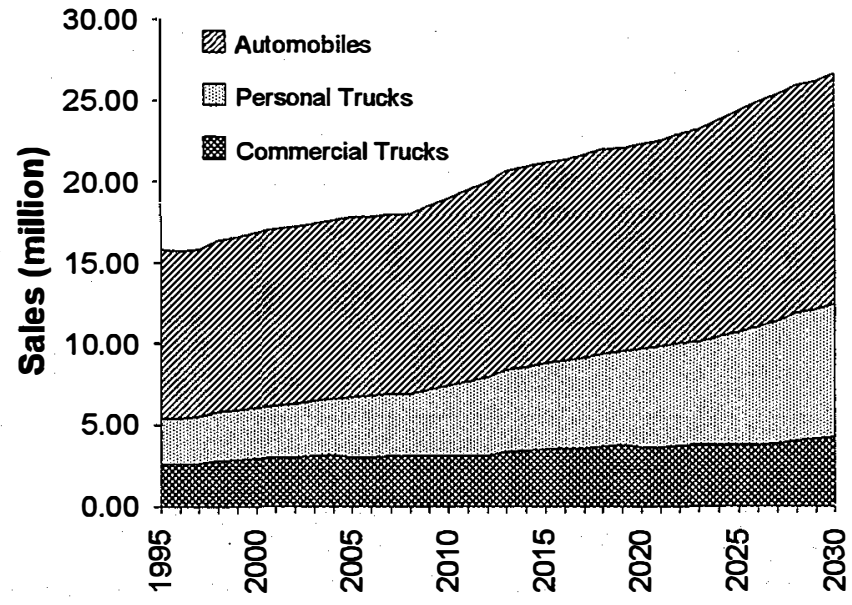

Figure 2. Projected new light duty vehicle sales

\footnotetext{
14 Not all the data used in this analysis are published in the AEO93. Supporting, detailed estimates of vehicle fleets and new vehicle sales that were used in the AEO93 were provided by David Chien of EIA.
} 
about 130,000 miles $(210,000 \mathrm{~km})$ for passenger cars, $150,000(240,000 \mathrm{~km})$ for light trucks used for personal transportation, and 225,000 miles $(362,000 \mathrm{~km})$ for commercial light trucks. ${ }^{15}$

\subsubsection{Vehicle Efficiency}

The conventional ICEV was assumed to achieve increased efficiency from 1990 through 2010, as reflected in EIA's estimates of the U.S. Environmental Protection Agency (EPA) Corporate Average Fuel Economy (CAFE) efficiency for new light duty vehicles (estimates for automobiles are shown in Figure 3). The fuel economy of new automobiles is projected to increase from 28.0 miles per gallon, or mpg, (11.9 $\mathrm{km} /$ liter) in 1990 to $34.6 \mathrm{mpg}$ ( $14.7 \mathrm{~km} /$ liter) in 2010; new light truck efficiency is projected to climb from a 1990 value of $20.7 \mathrm{mpg}$ (8.8 km/liter) to 25.4 (10.8 km/liter) in 2010 (EIA 1993). After 2010, the fuel efficiency of new ICEVs was held constant in the base case, and sensitivity runs in which ICEV efficiency continued to improve beyond that date (Figure 3, "ICEV extended") yielded little difference in overall results (see Section 4.1.4).

EPA CAFE tested performance is typically higher than the fuel economy actually experienced during onroad operation. This so-called "gap" between CAFE-tested performance and on-the-road efficiency is estimated to be $14.8 \%$ today for automobiles (25.0\% for light trucks), rising to $24.6 \%$ for autos (33.5\% for trucks) by 2010 (Maples 1993). Such estimates account for inaccuracy of the EPA testing procedure, increased congestion in the future, increasing urban versus highway driving, and higher highway speeds. Because of the large uncertainty about the size of these effects in the post-2010 time period, the 2010 estimates were held constant for the remainder of the analysis period.

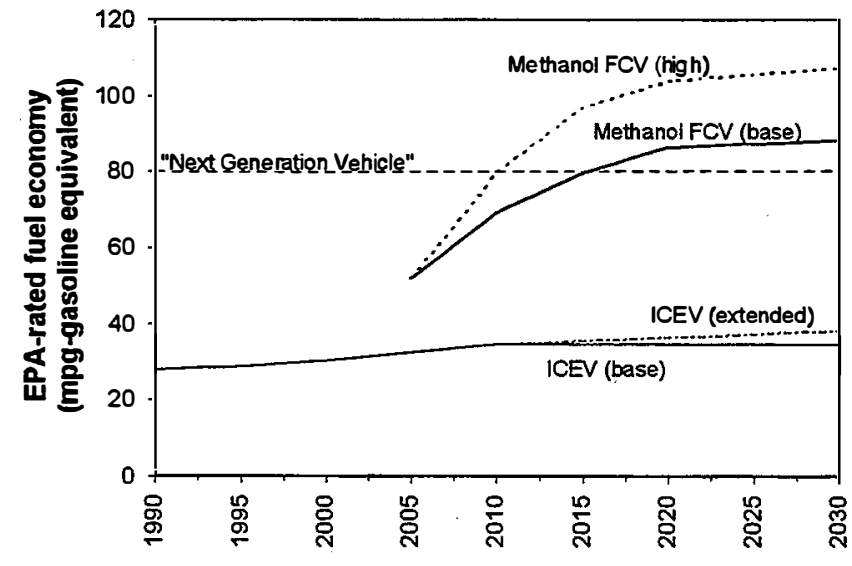

Figure 3. New automobile fuel economy assumptions

Two levels of efficiency improvement for FCVs were investigated for this analysis to assess the impact of achieving varying degrees of technical success (see Figure 3). ${ }^{16}$ Fuel economy is expected to increase rapidly in the first 15 years of prototype testing and commercial operation as a consequence of systems optimization and improvements in catalysts, reformer technologies, and auxiliary systems (e.g., compressors and pumps). Also, as fuel cell materials become less costly, powerplant stacks can be optimized to decrease current densities and increase overall efficiency. After the initial rapid increase, fuel economy is assumed to improve at a much slower rate through 2030 as additional

15 The average mileage values have been derived from Bureau of the Census (1990); R. L. Polk, as reported in Davis and Strang (1993); and EIA (1993).

16 Figure 3 shows our assumptions for new automobiles only; we assume that the relative fuel economy improvement for a fuel cell light truck versus a conventional light truck will be similar to the improvements shown in Figure 3 for automobiles. 
optimization is achieved. In the base case, the methanol FCV improves from 1.6 times as efficient as the conventional ICEV in 2005 to 2.0 times in 2010 (69.2 mpg-gasoline equivalent for automobiles; 50.7 mpg-equivalent. for trucks) and 2.5 times in 2020 (86.5 mpg-equivalent. for autos; 63.4 mpg-equivalent. for trucks). The high case follows a similar trend but represents a greater degree of technical and economic success in achieving fuel economy improvements.

Also shown in Figure 3 is the goal of the President's Partnership for a New Generation of Vehicles (PNGV), which seeks to develop a prototype vehicle that achieves an 80-mpg fuel economy level by 20042005 (Gates 1994). The Fuel Cells for Transportation Program is actively interfacing with this multiagency, public/private venture, as FCVs are a strong long-term candidate for meeting the initiative's goals. The high fuel economy scenario is consistent with the objectives of the PNGV initiative, as it assumes that an $80 \mathrm{mpg}$-equivalent fuel cell automobile running on methanol will be commercially available by 2010 , several years after the development of a production prototype that meets the initiative's time schedule.

Separate estimates were made of FCV performance if fueled by hydrogen stored on board the vehicle, which would increase vehicle efficiency as a result of eliminating the intermediate methanol-reforming step. An estimated $15 \%$ improvement over the methanol FCV is projected for the FCV operating directly on hydrogen, thereby enhancing the FCV's capacity to meet the goals of the PNGV initiative.

Note that fuel economy improvements for both the methanol and hydrogen FCV beyond 2010 are solely a result of changes in the powerplant and related electric vehicle systems, ${ }^{17}$ since the ICEV fuel economy is assumed to be static after that date in the base case. Should ICEV fuel economy continue to improve after 2010 (see Section 4.1.4), FCVs are assumed to maintain the same relative efficiency premium over the improved ICEVs. It is assumed that these gains would be achieved by reducing the size, weight, or aerodynamic drag of the vehicles, and changes in these characteristics (which do not involve the engine or power train) are assumed to apply equally to FCVs as ICEVs.

Unlike the ICEV, however, we assume that there will be no gap between the EPA-rated fuel economy for the FCV and its performance on the road. While there are multiple factors that cause such a gap for ICEVs, the two primary parameters are (1) the fact that, on average, vehicles travel more miles in an urban setting than is expressed by the $55 \% / 45 \%$ urban/highway split used by the EPA in rating vehicle fuel economy and (2) as population and urbanization increase, traffic congestion will grow as well. ${ }^{18}$ Both of these factors cause vehicles to travel at low speeds (where the internal combustion engine is less efficient) as well as increase the amount of idling time (in which the ICEV is consuming gasoline but not travelling). The FCV, however, should experience no penalty for operating at lower speeds; rather, the fuel cell stacks operate more efficiently at lower load (GM/Allison 1993), and (opposite of an ICEV) the

\footnotetext{
17 Regenerative braking, for example, will permit a significant portion of the energy expended to slow the vehicle to be recaptured and stored in batteries for use as propulsion energy. Such technology is currently being designed for battery-driven electric vehicles and will likely be transferred to the FCV. The current GM/Allison design incorporates regenerative braking (GM/Allison 1993), and achieving the fuel economy values used in the base and high cases of this analysis will probably require the use of regenerative braking.

18 Over two-thirds of the existing gap for ICEVs may be a result of these urban and congestion effects, and these two factors are estimated to cause over $80 \%$ of the future increase in the gap (Maples 1993).
} 
FCV is expected to have a higher fuel economy over the urban cycle than the highway cycle. Moreover, should the FCV incorporate regenerative braking, much of the energy used to stop the vehicle over the urban cycle can be captured and reused. Idling losses will also be low or nonexistent for an electrochemical engine, particularly if it can dump excess power to storage batteries on board the vehicle. Because of these factors, we assume that FCVs will experience no gap between their rated fuel economy over the EPA test and their on-road performance.

\subsubsection{Fuel Costs}

Fuel costs for gasoline, methanol $(\mathrm{MeOH})$, and hydrogen $\left(\mathrm{H}_{2}\right)$ were calculated based on projected feedstock costs and conversion, transmission, and distribution costs, as described below. Values in this section are presented on a per-gigajoule (GJ) or permillion Btu (MMBtu) basis and do not reflect the actual cost per unit of service (i.e., permile or per-kilometer traveled) to the consumer, which accounts for the higher efficiency of the FCV. Cost calculations that consider the relative fuel economies of different vehicles are made later in the analysis.

The costs (retail prices for consumers buying at service stations and into-vehicle costs for fleet operators having their own bulk fueling

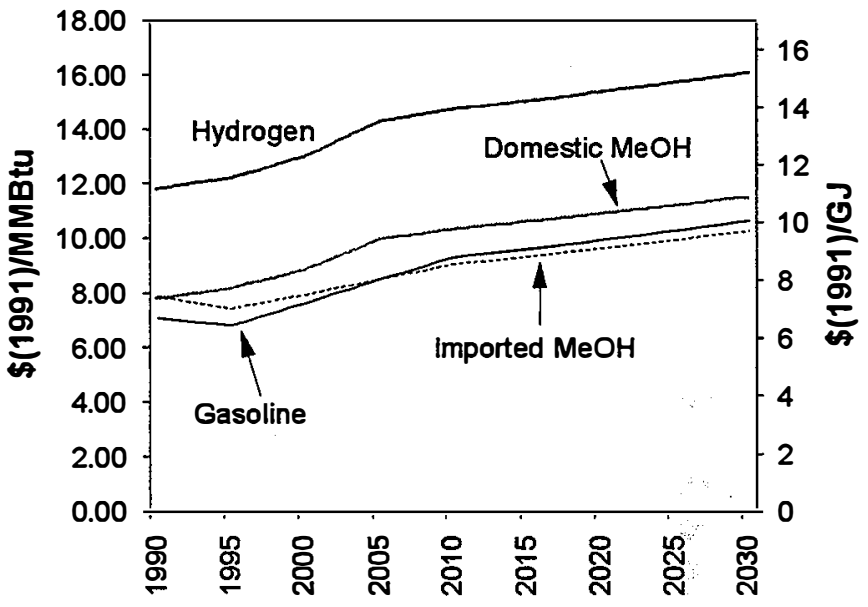

Figure 4. Assumed fuel prices for hydrogen, domestic methanol, and imported methanol from natural gas versus gasoline (excluding taxes) facilities) for methanol and hydrogen have been estimated on an "established industry" basis, excluding the higher costs and impacts on consumers of limited availability when the fuels first become available. Limited distribution of methanol is now being undertaken; a sizeable methanol distribution system may be developed if methanol receives more extended use as M85 or M100 in dedicated or flex-fuel vehicles. Methanol (particularly chemical grade) has been produced on a large scale from natural gas for decades. The distribution technologies and costs of methanol are sufficiently similar to those of gasoline and diesel fuel that substantial error in the estimates is unlikely. In the case of hydrogen fuel, however, the circumstances are quite different. Hydrogen is produced in large volumes and handled safely in high pressure and high temperature processes in the petroleum refining industry and is frequently transported by pipeline for moderate distances. There is no experience in retail distribution of high pressure hydrogen for personal vehicles, and operational and maintenance standards may be difficult to control in this setting. Neither is there any experience in laying and operating hydrogen pipelines in residential and commercial sections of urban areas. Therefore, the hydrogen costs used in this study are largely untested. The feasibility of small-scale reforming and compression has been assumed to become feasible in some cases. Nonetheless, the cost of hydrogen, even at research target levels used in this study, exceeds that of methanol by a small margin. In addition, the question of the availability of resources for petroleum, methanol, or hydrogen fuels in the very long range (post-2030 time period) may influence the choice of alternative fuel systems. Additional study is needed to define the optimum fuel and its distribution system for fuel cell vehicles. 


\subsubsection{Fuel Taxes}

Fuel costs for both ICEVs and FCVs were calculated excluding federal, state, and local motor fuel taxes (see Figure 4). The inclusion of taxes on a volumetric basis would bias the analysis in favor of gasoline (because of its higher energy density relative to methanol and hydrogen) whereas the use of an energy basis for taxation would favor FCVs if the intent of taxes were to impose a fee related to vehicle miles driven. Elimination of motor fuel taxes places the alternative vehicles on an equivalent basis per vehicle mile for each class of vehicle. The issue of whether taxes might be used to encourage the use of one fuel rather than another is not addressed.

\subsubsection{Gasoline}

The price of gasoline was taken from the AEO93, reduced by the average gasoline taxes per gallon as projected by EIA. The price of gasoline after 2010 was escalated with changes in the price of crude oil by adding $110 \%$ of the increase in the crude oil price per unit of energy to the price per unit of energy of gasoline (the 10\% factor represents the energy consumed in gasoline manufacture [DeLuchi 1991]). The marketing and distribution costs (margins) estimated by EIA (1993) were identified, and the same per-gallon quantities were also used in deriving costs for methanol.

The EIA projections of crude oil prices, on which the gasoline prices are based, were used to determine the savings from reduced imports of crude oil (see Figure 5). The EIA crude prices were also used in estimating the alternative value of foreign natural gas in the liquefied natural gas (LNG) markets, described later. The EIA projections include a high and a low case, as well as the base projection, permitting the reader to estimate the impact of other assumed levels of crude prices by interpolation or extrapolation. For example, the low crude oil price case can be used to test the sensitivity of the results to lower gasoline prices as the result of a market (or Organization of Petroleum Exporting Countries [OPEC]) response to encroachment by alternative fuels.

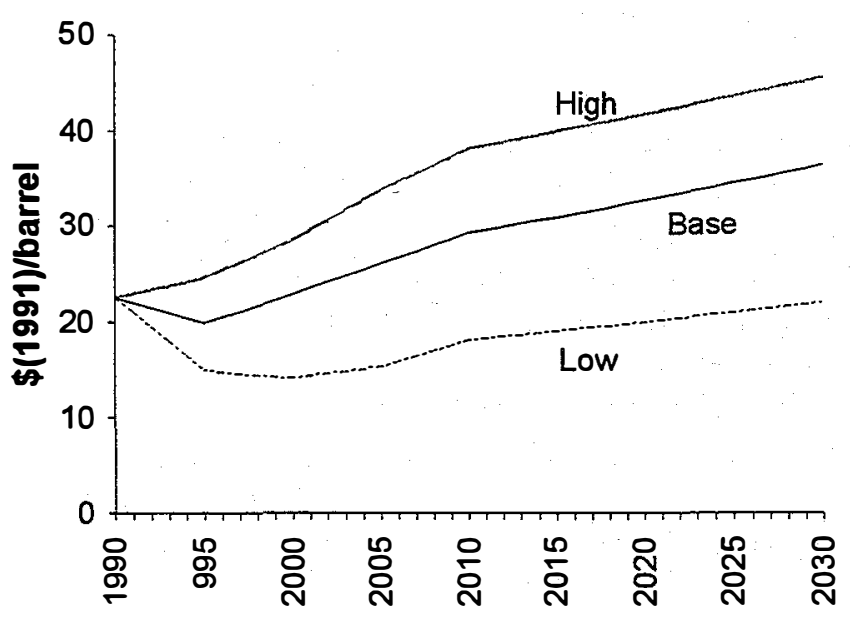

Figure 5. Crude oil price projections

\subsubsection{Methanol from Domestic Natural Gas}

The price to consumers of methanol fuel (Figure 4) was developed assuming that production would be from both domestic and foreign natural gas. Methanol for chemicals and other uses has been produced on a large-scale for decades. The recent expansion of methyl tertiary butyl ether (MTBE) production nationwide and marketing of methanol motor fuel in California have expanded the market and led to some capacity expansion for methanol production, both in the United States and other countries. Production 
cost estimates were taken from DOE (1989), and the efficiency of conversion was assumed to be $65 \%$ on an energy basis. While slight advances in natural gas/methanol production technologies may occur over time, this conversion efficiency corresponds to a state-of-the-art facility in a technologically mature industry. The feedstock was priced at the average wellhead value of natural gas (EIA 1993), plus a transportation charge for high load-factor shipments from the field to the conversion plants (most of which would be near the producing fields while also located on or near the petroleum product pipeline systems) (GRI 1992). The methanol would then be shipped via pipeline or barge to bulk plants. The balance of the distribution would be analogous to that of gasoline, and the costs are assumed to be the same as gasoline on a volumetric basis (i.e., nearly twice the cost on an energy basis, methanol being about half as energy-dense as gasoline).

Domestic natural gas supplies are projected to grow in the future with the expansion of demand. The addition of a substantial increment of demand to satisfy transportation fuel needs could have a significant impact on gas supplies and their prices. Although the potential gas supply is very large-several times greater than the proven reserves-at issue is what price is needed to bring additional supplies to market. The high FCV market penetration case would add about 5 quadrillion Btu (quad) (5.3 exajoules, or EJ) demand for natural gas to produce methanol or hydrogen in $2030 .{ }^{19}$ Sufficient overseas gas resources exist to produce half or more of this demand if methanol were the fuel of choice, although domestic supplies could meet all the demand, supplemented by pipeline imports of gas from Canada and Mexico, which could expand under the recent North American Free Trade Agreement (NAFTA). ${ }^{20}$ The extent of any price increase is uncertain. The EIA projections of gas prices by 2010 (which do not include substantial demand increases in the transportation sector) and, as extended, by 2030 are higher than those made by some gas industry analysts. Moreover, the projections of gas prices have been progressively reduced from year to year, reflecting the continued improvement in gas production and exploration technology as well as the substantial reduction in the industry's cost structure that has occurred since 1982. ${ }^{21}$ Hence, it is unlikely that major increases in gas costs above those projected by EIA would occur before 2025, even in the high penetration case.

\subsubsection{Imported Methanol from Foreign Natural Gas}

The cost of methanol produced overseas from natural gas includes the cost of the feedstock, the capital and operating costs of the conversion plants, and the cost of shipment to U.S. markets (Figure 4). Large quantities of natural gas are available in a number of countries where local demand is currently inadequate to use the available resources. In some such countries, such as Mexico, Canada, the Russian Federation, Algeria, the Netherlands, and Norway, markets in adjacent countries provide attractive export markets

\footnotetext{
19 Although projections have not been made in this analysis of total natural gas consumption for all energy sectors in 2030 , for comparison's sake 1990 total U.S. natural gas consumption was 19.3 quad (20.4 EJ) and is projected to increase to 25.0 quad (26.4 EJ) by 2010 (EIA 1993). Using the implied growth rate in EIA (1993), 2030 U.S. natural gas consumption could climb to over 30 quad ( $32 \mathrm{EJ}$ ) by 2030 , and the additions imposed by the high FCV case would then constitute approximately a $15 \%$ increase in demand.

20 In the past, the Government of Mexico has banned exports of gas to the United States and cancelled standing export agreements. This situation is likely to change under NAFTA.

21 See GRI (1993) and Hudson (1988) for a discussion of the numerous factors involved.
} 
via pipeline. In others, such as Indonesia, Brunei, South Alaska, Malaysia, Australia, Algeria, and Abu Dhabi, natural gas has been sold for export as LNG. A number of countries export natural gas after its conversion to methanol. The countries most likely to export large quantities of methanol are those with limited higher value uses either in domestic markets or adjacent markets that are served by pipeline. The exporting countries would export natural gas to the market providing the highest netback value for the resource. ${ }^{22}$ However, a country would be assumed not to allow use of its resources unless, at a minimum, direct production costs were covered and a significant net benefit to the economy existed; otherwise, the resource would be retained until market conditions changed or an alternative use appeared. In the case of LNG, the costs to be covered by the sales revenue include gathering system costs, gas-processing costs and losses, LNG-liquefaction plant costs, export terminal costs, LNG tanker costs and in-transit losses, duties and storage costs at the destination, and any marketing costs. The price received for the LNG in the destination country would be competitive with that of heavy fuel oil for industrial users or, after local gas system distribution costs, with distillate fuel or kerosene for the residential markets.

Significant quantities of natural gas appear to be available in Central Africa, Southeast Asia, and South America that could be produced and sold in Japan, Europe, or North America as LNG or to the United States (and other countries) as methanol. We assumed that the minimum acceptable price of the feedstock would be the higher of $\$ 0.50$ per million Btu $(\$ 0.47 / \mathrm{GJ})$, a minimum estimate of production cost, or the alternative netback value of the gas if sold as LNG. Estimates of LNG processing, tanker shipment, and re-gasification costs (DOE 1989), estimates of crude prices (EIA 1993), and estimates of tanker shipment distances (DOE 1989) were used to derive the estimates of natural gas netback values for this study.

The processing cost of methanol for a Class III foreign location (developing country, minimum infrastructure) and a $20 \%$ rate of return (in constant dollars) were used, as reported in DOE (1989). The transportation cost for methanol to U.S. ports was based on costs for tankers of sizes that are capable of entering U.S. ports having refineries or large fuel-products terminals available for unloading and distribution. It is assumed that imported methanol would be used near the coasts and domestic-source methanol would be consumed primarily at inland locations.

\subsubsection{Hydrogen from Natural Gas}

The price of hydrogen produced by the steam reforming of natural gas was based on the cost of steam reforming and an energy conversion efficiency of $69 \%$ (higher heating value basis) (NHA n.d.). Largescale reforming of hydrocarbons for joint production of hydrogen and gasoline blend stocks has been undertaken for years in refineries, as has production of hydrogen from methane and other refinery gas streams. The distribution cost of hydrogen by pipeline to service stations, assuming production is undertaken in large central plants in or near larger cities, is very uncertain. Estimates from Ogden and Nitsch (1992) were used for this study. Similarly, the compression and storage costs for service stations are uncertain; the estimates used are probably on the high end, as they do not reflect the lower costs of

\footnotetext{
22

In comparison to other measures of commodity prices (cost, insurance, freight [CIF] or free on board [FOB]), the netback value at the wellhead provides a better measure from a national welfare perspective, as it adjusts for the costs incurred in serving each of the alternative markets. Netback value is defined as the net revenue to the government and producing organization (govemment or private) after payment of all development, gathering, processing, shipping, tariffs, unloading, storage, and distribution costs. It includes the government's taxes or profit-sharing from all stages of the process that exceed the minimum retum on investment appropriate for any funds invested by the government.
} 
compressors and tanks that are likely to be achieved in a mature industry under mass production and highly competitive conditions.

The cost of transmitting hydrogen via pipeline is very uncertain. As a result, one of the parametric studies assumes that hydrogen is not transported by pipeline, but is produced in small-scale natural gas reformers at service station (or major fleet customer) sites. The cost differential between central and local production appears to be small. In addition, a parametric study was made of photovoltaic production of hydrogen at the refueling site; again, little difference in cost was noted, assuming cost targets were met.

\subsubsection{Altemative Sources of Methanol and Hydrogen}

Several alternative sources of methanol and hydrogen were briefly considered to identify the potential change in benefits resulting from a shift away from natural gas feedstocks. Methanol from biomass might be less expensive than that produced from natural gas if DOE cost targets are achieved. Methanol can also be produced from coal; however, the cost of high-temperature, high-pressure cracking of large molecules, plus the environmental consequences of large-scale expansion of coal mining, make coalsourced methanol a higher cost alternative to biomass methanol (Hudson 1989). In the case of hydrogen, development of efficient small-scale reformers might allow reforming to occur at the service station, avoiding the pipeline distribution of hydrogen in both urban and rural areas. Also, hydrogen could be produced by direct photoconversion processes, by electrolysis using power from photovoltaic cells, or through biomass gasification. Many of these alternative options have the potential for even larger economic and environmental savings than those estimated in the base case of this study, which assumes natural gas will be the primary feedstock. Results of parametric studies that include these alternative sources are discussed in Section 4.1.4.

\subsection{Emissions Reductions}

The environmental analysis focuses on emissions of interest for local air quality-namely the regulated pollutants $\mathrm{NMOG}_{2}{ }^{23} \mathrm{NO}_{x}$, and $\mathrm{CO}$-as well as $\mathrm{CO}_{2}$ because of its important role in global climate change. While this study deals with these two primary areas of environmental concern, other important residuals associated with transportation energy use include toxic air emissions, particulates, sulfur oxides, other greenhouse gas emissions besides $\mathrm{CO}_{2}$, surface and groundwater contamination resulting from fuel spills and leaks, and solid and water wastes from fuel conversion facilities.

Traditional environmental analyses of the transportation sector have focused exclusively on emissions from the vehicle tailpipe. While this analysis confirms that these "tailpipe" emissions are in fact a primary

23 Several terms are typically used to describe organic compounds of interest to air quality. The term non-methane hydrocarbon (NMHC) has traditionally been used in mobile source emissions characterization, and the current standards for conventional vehicles are expressed as NMHC. However, measurements of NMHC do not capture emissions of oxygenated hydrocarbons and aldehydes, both of which are of key importance when studying the use of alcohol fuels. Since we consider the use of methanol as a fuel for the FCV in this analysis, it is more appropriate to express emissions in terms of NMOG, a category that includes all of the compounds covered by NMHC plus oxygenated hydrocarbons and aldehydes. To be consistent with the FCV analysis, we must also measure emissions from conventional vehicles in terms of NMOG, even though the standards apply to NMHC only. In reality, the use of gasoline does not release substantial quantities of oxygenated hydrocarbons or aldehydes, and the difference between NMHC and NMOG emissions for vehicles operating on gasoline is negligible. 
component of transportation-related emissions, it also shows that the air emissions associated with producing and distributing the fuel to the end user are not small. In characterizing these so-called "upstream" activities, the assessment of environmental benefits described here uses a total fuel cycle approach that considers the "cradle to grave" impacts of fuel use, i.e., from feedstock extraction to fuel production through final end use. A total fuel cycle will also consider the life cycle components of energy use, such as the energy and emissions associated with manufacturing energy technologies (e.g., vehicles).

\subsubsection{Upstream Emissions}

Because total fuel cycle analysis is still in its nascent stage, the data and tools required for conducting such comprehensive reviews of energy usage are largely underdeveloped. Our assessment of the upstream stages of the fuel cycle relies on the limited data collected and compiled by other researchers (primarily DeLuchi [1991]; DeLuchi, Wang, and Greene [1992]). While we have sought to update these data where necessary and possible, the results of this work indicate that upstream emissions are important enough to warrant a more thorough study of the gasoline, hydrogen, and methanol fuel cycles.

Components of the fuel cycle that are characterized in the upstream environmental analysis include (see Figures 6-8): the extraction of feedstocks (crude oil and natural gas); feedstock transmission (crude oil tankers, rucks, and pipelines; natural gas pipelines); fuel conversion (oil refinery, methanol conversion plant, hydrogen conversion plant); and fuel distribution (gasoline, methanol, and hydrogen fuel networks). Also included in the upstream analysis are emissions associated with assembling vehicles and the use of energy to manufacture the raw materials for vehicle production.

Emissions associated with these upstream activities are calculated based on DeLuchi (1991), who estimates upstream emissions from a variety of alternative fuel cycles in 2000. While DeLuchi presents data for

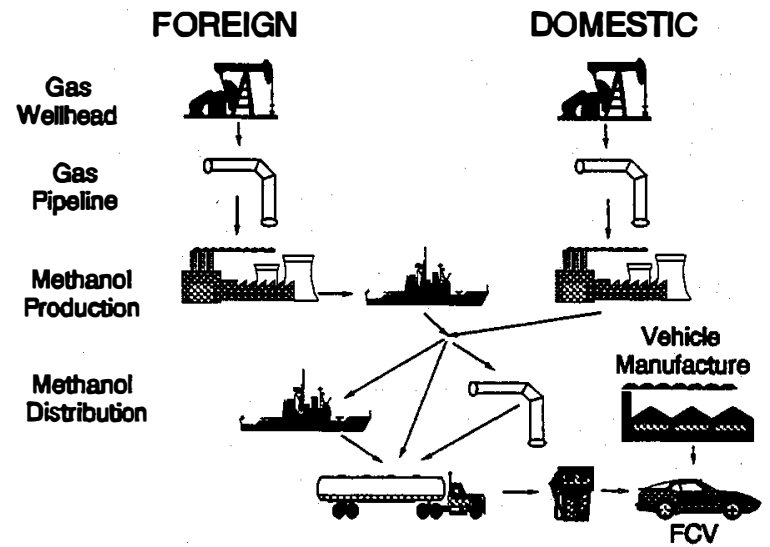

Figure 6. Reformulated gasoline fuel cycle a baseline conventional vehicle operating on reformulated gasoline, used in this analysis with few adjustments, detailed estimates are not reported for fuel cell vehicles. ${ }^{24}$ Data for the methanol FCV and hydrogen FCV were thus derived from estimates for a methanol ICEV and a compressed natural gas ICEV, respectively. The underlying assumption is that the emissions from the production and distribution of methanol for a FCV will be identical to those from methanol supplied to an ICEV. In the case of hydrogen, we have estimated the emissions associated with converting natural gas to hydrogen in a conventional steam reforming process and added them to the emissions from producing pipeline quality natural gas as estimated by DeLuchi.

\footnotetext{
24 While total fuel cycle emissions data are reported for fuel cell vehicles in DeLuchi (1991) and in more recent studies, they are presented as aggregated $\mathrm{CO}_{2}$-equivalents. Therefore, the value of individual emissions (i.e., $\mathrm{NO}_{\mathrm{x}}$ versus $\mathrm{CO}$ versus $\mathrm{CO}_{2}$ ) cannot be determined from the published work.
} 
Hydrogen is assumed to be produced via steam reforming of natural gas, followed by purification (we assume the pressure swing adsorption process) and compression for storage on board the vehicle. Steam reforming of natural gas is assumed to be the primary source of emissions from hydrogen production (EA Mueller 1990). Reformation is a high temperature process (the gas stream exiting the reformer is at about $800^{\circ} \mathrm{C}$ [NHA n.d.]), and a portion of the natural gas input is combusted to provide the necessary heat. As a supplement, waste gas from the hydrogen purification process (which contains $\mathrm{CO}$, methane $\left[\mathrm{CH}_{4}\right], \mathrm{CO}_{2}$, hydrogen $\left[\mathrm{H}_{2}\right]$, and other compounds) is often burned along with natural gas to heat the reformer. A typical hydrogen conversion facility might meet $40 \%-80 \%$ of its reformer energy requirements with waste gas (Abrardo 1994).

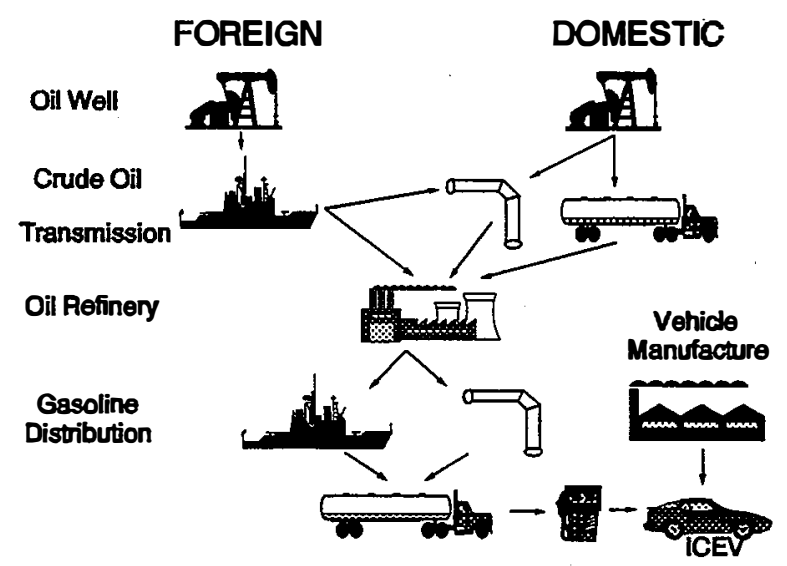

Figure 8. Hydrogen from natural gas fuel cycle

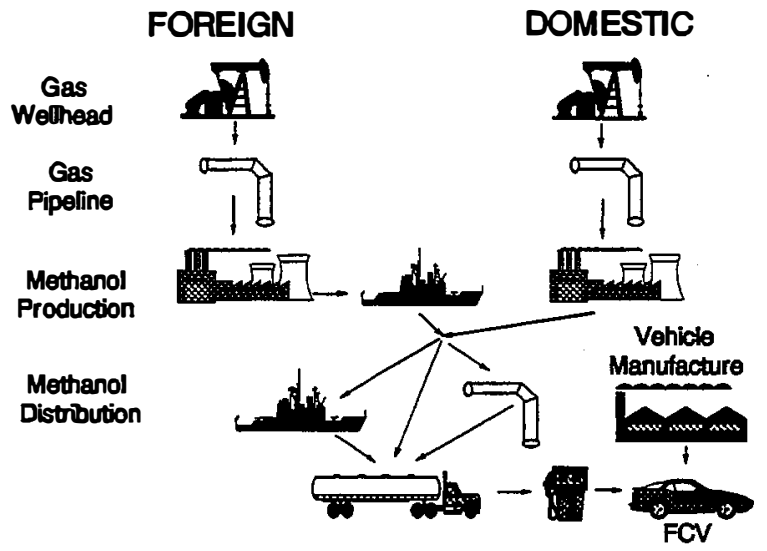

Figure 7. Methanol from natural gas fuel cycle
Emissions from natural gas combustion are available in EPA's AP-42 document (EPA 1993). Kunz et al. indicate that EPA's estimates of $\mathrm{CO}$ emissions for natural gas combustion are reasonable for use in characterizing emissions from large-scale steam reformation fired by a mixture of natural gas and waste gas (Kunz et al. 1992); we assume the same is true for NMOG. Because the waste gas that provides supplementary heat to the reformer contains large volumes of inert gases (e.g., $\mathrm{CO}_{2}$ ), the flame temperature upon combustion of the natural gas/waste gas mixture is lower than that of pure natural gas, and the resulting $\mathrm{NO}_{x}$ emissions for the reformation process are lower than reported in AP42 (Kunz et al. 1992). The values for steam reforming used in this analysis are $(\mathrm{lb} / \mathrm{MMBtu}$ of fuel burned to heat the reformer): $0.07\left(\mathrm{NO}_{x}\right), 0.034$ (CO), and 0.0027 (NMOG). ${ }^{25}$ configurations, but the values used here fall within the boundaries of the range of published values (see, for example, EA Mueller [1990]; IFC [1986]).
} 
Energy requirements for compressing and distributing hydrogen for hydride storage ${ }^{26}$ on board a FCV are estimated to be similar to the energy consumed in compressing and distributing compressed natural gas on a per-Btu-delivered basis (DeLuchi 1991), and thus DeLuchi's estimates of emissions from compressions and distribution in the natural gas fuel cycle are used directly in the hydrogen fuel cycle analysis here.

Given the above adaptations and adjustments to DeLuchi's calculations, Table 1 shows the estimates of upstream emissions used in this analysis.

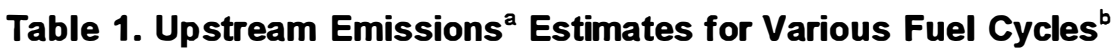
( $g / G J$ of fuel delivered to the end user)

\begin{tabular}{|c|c|c|c|}
\hline & Reforvulated & Metianol from & Hydrogen fron \\
\hline NMOG & $21 \%$ & 16. & 22 \\
\hline $\mathrm{NO}$. & 78 & 191. & 159 \\
\hline 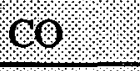 & 46. & 35. & 30 \\
\hline $\mathrm{OO}_{2}$ & 30,300 & 43.500 & $11,2,000$ \\
\hline
\end{tabular}

- Includes feedstock extraction and transmission, fuel conversion and distribution; and vehicle manufacture.

- Adzpted from DeLuchi (1991).

c $\mathrm{CO}_{2}$ emissions from upstream activities only. The use of gasoline and methanol on board the vehicle will emit additional $\mathrm{CO}_{2}$.

In all cases, the conversion process (i.e., gasoline refining from crude oil; natural gas reforming to produce hydrogen and methanol) dominates the energy requirements and resulting emissions from the upstream activities of the fuel cycle. Because of their low energy densities relative to gasoline, fuel distribution for methanol and hydrogen are also important stages of these fuel cycles.

A portion of the upstream emissions shown in Table 1 are from vehicle manufacture, which includes the emissions from assembling the vehicle itself as well as those from producing the major materials used in vehicle production (e.g., steel, glass, and aluminum). DeLuchi's work does not identify emissions resulting from vehicle manufacture separately from the remainder of upstream activities. Strictly speaking, these are fixed for each vehicle type and do not depend, as the above table implies, on the

\footnotetext{
26 While considerable uncertainty exists regarding future hydrogen storage technologies, compressed storage in tanks (similar to natural gas storage on board CNG vehicles) might be a more reasonable assumption, particularly in the early years of FCV use. Because hydrogen is less energy dense than natural gas, however, it takes at least three times as much energy to compress a Btu of hydrogen than it does a Btu of natural gas. Thus, assuming hydrogen is compressed to the same pressure as a typical natural gas compressed storage tank, energy requirements for this stage of the fuel cycle would increase at least three-fold. Given the level of aggregation in DeLuchi's data, however, this adjustment cannot be made. Thus, we assume hydride storage will be used for FCVs (which requires lower pressures than compressed storage), with the important caution that energy use and resulting emissions may be somewhat higher should compressed storage prevail as the dominant on-board storage technique.
} 
amount of fuel delivered to the vehicle. The overall effect of this error is anticipated to be small, since DeLuchi's estimates for the energy embodied by a vehicle (i.e., energy required to manufacture vehicle materials and assemble them) indicate that they are roughly $10 \%$ of the total motor fuel energy consumed by the vehicle over its lifetime.

\subsubsection{Conventional Vehicle Emissions}

Air emissions from the vehicle itself are the primary environmental concern associated with transportation technologies, as in many areas they are the largest contributor to local air quality problems. Since the 1970s, emissions of $\mathrm{CO}, \mathrm{NO}_{\mathrm{x}}$, and hydrocarbons have been regulated under the Clean Air Act, and the recent revisions to the Act (the 1990 Clean Air Act Amendments) will make future emissions regulations even more stringent. In addition to the federal standards, individual states may "opt in" to the standards promulgated by the state of California under its Low Emissions Vehicle (LEV) Program to achieve lower levels of mobile-source emissions. While these standards are a critical starting point for estimating emissions levels, this analysis goes a step further to project future emissions from conventional vehicles with a model frequently used by local air quality planners. The following sections outline the assumptions made regarding the stringency of future emissions requirements and the data generated as part of the emissions modeling work.

Tailpipe emissions of $\mathrm{CO}_{2}$ are not included in the modeling activity. Instead, they are directly calculated using the carbon content of the fuel combined with the efficiency of the end-use vehicles. The values used in this report are from DeLuchi (1991) and, because they vary directly with vehicle fuel economy, are treated similarly to the upstream emissions in the analysis (described previously).

The ICEVs used as the base case for the environmental analysis are light duty vehicles (both cars and light trucks) operating on reformulated gasoline. Public interest and more stringent standards are currently driving the gasoline market towards formulas associated with lower tailpipe and evaporative emissions, and it is assumed that such reformulated blends will begin to play a large role in the future fuel market for ICEVs. ${ }^{27}$ If reformulated gasoline does not begin to enter the transportation market to the degree assumed here, then ICEV vehicular emissions will be higher than estimated in this analysis, resulting in even larger benefits from a transition to FCVs.

MOBILE5a was used to predict future emissions of $\mathrm{CO}, \mathrm{NMOG}$, and $\mathrm{NO}_{\mathrm{x}}$ from conventional light duty autos and trucks. The model was developed by EPA to enable modeling of vehicular emissions for local air quality planning. The model has evolved over many years of use and currently incorporates a sophisticated series of inputs and variables such that relatively specific and detailed scenarios can be generated for vehicular emissions. Input data for the model are based on extensive data collection in which empirical information on actual in-use emissions indicates how vehicles perform over various driving cycles (including vehicle speeds, length of trip, and starting and resting characteristics), how their emissions deteriorate over time, and how specific control programs (such as inspection and maintenance) affect emissions. Based on this internal data, along with inputs regarding the level of standards, types

\footnotetext{
27 Beginning in 1995, reformulated gasoline must be sold in the nine worst ozone non-attainment areas (those that do not attain the National Ambient Air Quality Standards) with populations over 250,000. Other ozone non-attainment areas may also opt in to the program to help achieve their air quality goals.
} 
of controls in effect, average vehicle speed, location, fuel specification, and numerous other assumptions, MOBILE5a calculates emissions from all major vehicle classes.

\subsubsection{Standards and Controls}

We have assumed that future emissions controls for conventional vehicles will be more stringent than for today's vehicles and have input the following requirements into our modeling runs: use of a low-volatility summertime reformulated gasoline blend on a national basis, an enhanced inspection/maintenance program, an anti-tampering program, and on-board and pump-side evaporative emissions controls. For the base case, it is assumed that the Tier I standards of the 1990 CAAA will be fully implemented by 1998 (i.e., $100 \%$ of the vehicles sold in that year and after will satisfy the new standards), as is currently mandated by federal law. ${ }^{28}$ EPA is presently considering a second set of more stringent standards, the Tier II standards, and the agency is required to submit a report to Congress by June 1, 1997, assessing the necessity and feasibility of reaching these lower emissions standards.

In addition to the federal standards, the 1990 CAAA allow areas to adopt the California LEV Program requirements if they need more mobile-source pollution control than the national program can provide. Adopting the LEV standards will result in emissions levels lower than the Tier II standards, except in the case of CO, where the California standard for all but a small fraction of vehicles is equal to the higher Tier I federal standard. Although several vehicle types may compete for the LEV market, we assume that the majority of vehicles complying with the LEV Program will be conventional vehicles operating on reformulated gasoline that employ electrically heated catalysts and, if necessary, heated fuel-preparation systems. In our low emissions scenario, we assume that all states will opt-in to the LEV Program by 2010 , thereby applying the standards nationwide. While the reasonableness of the assumption is clearly debatable, it is used to provide a lower bound on the gasoline vehicle emissions for the purposes of this analysis.

\subsubsection{Urban versus Highway Driving}

MOBILE5a calculates vehicular emissions as a function of speed. Based on empirical data, EPA demonstrates that the emissions of NMOG and CO are high at low average speeds but decrease (at first rapidly, then more slowly) as average speed increases, reaching a minimum level of emissions at an average speed of $48 \mathrm{mph}(77 \mathrm{kph})$. As a result, emissions of NMOG and CO in urban areas, where average speeds are typically low, are much higher than those from highway driving. Conversely, $\mathrm{NO}_{\mathrm{x}}$ emissions reach a minimum at low average speeds, and thus emissions over the highway driving cycle are actually higher than during urban driving. In modeling urban driving, we have assumed an average speed of $19.6 \mathrm{mph}$ (31.5 kph), which is the average achieved over the Federal Test Procedure (FTP) used by EPA for emissions certification. The assumed average highway driving speed is $48.5 \mathrm{mph}(78.0 \mathrm{kph})$, equal to the average speed over the federal highway driving cycle that EPA uses to determine highway fuel economy for reporting purposes (such as on the sticker found on the window of new vehicles). To develop emissions for vehicles on a national aggregate basis, emissions over the urban cycle and the

\footnotetext{
28 However, as the following discussion describes, actual in-use emissions are typically much higher than the mandated certification standards. While regulations are a key input to emissions models, the use of MOBILE5a more accurately projects future emissions by accounting for deterioration, poor maintenance, and other factors that affect emissions characteristics.
} 
highway cycle were weighted to reflect the respective fractions of total vehicle miles traveled by each mode. In 1987, urban driving accounted for $62.9 \%$ of the total miles traveled by automobiles and $55.4 \%$ of light truck miles, and these shares are expected to increase to $71.4 \%$ (cars) and $64.7 \%$ (light trucks) by 2010 (Maples 1993). ${ }^{29}$

\subsubsection{Time Period}

MOBILE5a is typically run by local air quality planners interested in constructing emissions scenarios for their current or near-term fleets, projecting perhaps 10-15 years into the future. The goal of this analysis, however, is to develop national-level emissions estimates through 2030. Strictly speaking, MOBILE5a is only designed to project through 2020. In this analysis, we have extended the use of MOBILE5a beyond 2020 under the reasoning that, as long as emissions standards and vehicle characteristics (such as deterioration rates) do not change in the post-2020 timeframe, modeled emissions for each vehicle added to the fleet after 2020 will be unchanged. Aggregate fleet emissions, however, do change as a result of changes in the vehicle age distribution, as discussed in the following section.

\subsubsection{Vehicle Age Distribution}

MOBILE5a is usually run to determine emissions from the total vehicle fleet in a particular area. This analysis, however, is only interested in emissions from the subset of the total fleet that would be replaced by FCVs. As a result, the default distribution of vehicles by age in MOBILE5a is modified to reflect the distribution, in each year, corresponding to only the fleet of ICEVs that FCVs replace. Thus, if 10,000 FCVs are sold in 2010, they have replaced 10,000 ICEVs, all of which are new. If 20,000 FCVs are then sold in 2011, a total of 30,000 ICEVs have been displaced by 2011 ,

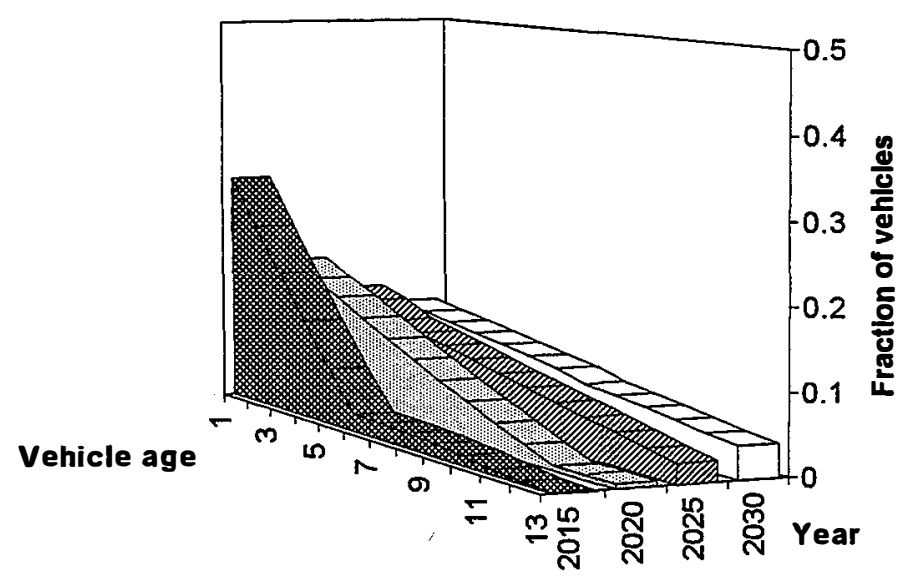

Figure 9. Age distribution of displaced ICEVs in select analysis years $66 \%$ of which are less than one year old and $33 \%$ of which are one-year old. Because emissions performance deteriorates substantially over the life of the vehicle, the vehicle age distribution in each year is critical to determining the average annual fleet emissions. Figure 9 shows the vehicle age distributions assumed for specific years of the base case analysis. In the near term, 2015, the majority of ICEVs displaced by FCVs would be relatively young; however, as time progresses, the age distribution of the displaced fleet levels out. 


\subsubsection{Model Outputs}

Even under the assumption that relatively stringent controls will be applied to motor vehicles in the future, runs of MOBILE5a indicate that future emissions will be well above the CAAA standards. This is a result of at least three factors: (1) vehicles, when certified for compliance with the CAAA regulations, are run on a pure indolene fuel that has less impurities than the gasoline available to consumers at the pump, (2) in actual use, vehicles are rarely maintained to the degree necessary to attain the standards, and (3) even with an inspection/maintenance program in effect, a small group of "high emitters" (vehicles that are broken or have been tampered with) exist that can greatly increase average emissions of the fleet. In

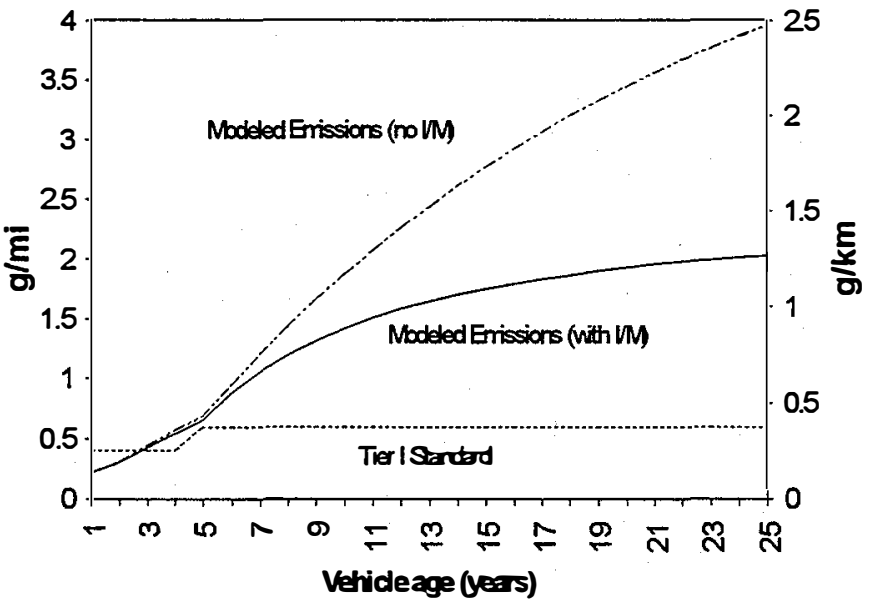

Figure 10. Modeled $\mathrm{NO}_{x}$ emissions versus standards for automobiles, by vehicle age particular, emissions performance appears to be closely linked with vehicle age, and Figure 10 demonstrates the large increases in $\mathrm{NO}_{\mathrm{x}}$ emissions associated with older vehicles. ${ }^{30}$ Emissions increase rapidly during the first 10 years of operation and, by the end of the third year of vehicle life, have surpassed the standard. The standards do permit a slight increase in emissions after the first 5 years or 50,000 miles $(80,000 \mathrm{~km})$ of operation, but not nearly enough to compensate for the deterioration rates expressed by MOBILE5a. As a result, average grams/mile emissions of a light duty automobile operating under an I/M program are 1.6-3.0 times greater than the CAAA standard. ${ }^{31}$ Figure 10 also demonstrates the large potential benefit from an inspection/maintenance program, as the deterioration rates are substantially reduced when an enhanced $\mathrm{I} / \mathrm{M}$ program is assumed in the model.

The use of standards in estimating vehicle emissions can largely underestimate actual in-use emissions, even if we assume that the vehicles are subject to a fairly rigorous inspection and maintenance program, as we have here. Similarly, comparisons with actual measured data indicate that the use of the MOBILE5a itself may underestimate in-use emissions. One of the important contributors to this phenomenon is that MOBILE5a uses emissions coefficients derived from testing vehicles over the Federal Test Procedure (FTP), which designates a driving schedule that is designed to be "representative" of vehicle use. The accuracy of the FTP in modeling actual driving behavior has recently come into question, and this issue is currently under review (German 1993). Even if the FTP is fairly accurate in representing the behavior of most drivers, the small percentage of drivers who are more aggressive than the average may account for a disproportionately large share of the total emissions. Finally, the impact

\footnotetext{
30 We have only presented data for $\mathrm{NO}_{\mathrm{x}}$; however, curves for NMOG and CO follow the same upward trend.

31 This assumes that the average automobile life is 13 years and accounts for higher mileage in the first 5 years of operation (Davis and Strang 1993), when emissions are lowest.
} 
of high emitters is beginning to be better understood, and recent results indicate that approximately half of the emissions of CO and HC may come from only 10\% of the vehicles (Stedman et al. 1991; Stedman, Bishop, Peterson, and Guenther 1991). A combination of these factors can result in measured average emissions exceeding those of the MOBILE5a model outputs by up to a factor of two for recent model vehicles (Calvert, Heywood, Sawyer, and Seinfeld 1993).

\subsubsection{Fuel Cell Vehicle Emissions}

Vehicular emissions for the hydrogen FCV are zero, since the only by-products of vehicle use are small amounts of heat and water. Vehicular emissions for FCVs operating on methanol and using an on-board reformer are very low; however, because methanol is a carbon-based fuel, $\mathrm{CO}_{2}$ will be released during the operation of the reformer. ${ }^{32}$ In addition, the on-board storage of methanol will result in small amounts of evaporative NMOG emissions, and the operation of the on-board reformer is expected to release limited quantities of $\mathrm{CO}, \mathrm{NO}_{\mathrm{x}}$, and $\mathrm{NMOG}$.

Evaporative NMOG emissions are estimated from reported values for a methanol-fueled ICEV, with adjustments for the decreased fuel requirements of the FCV. Evaporative NMOG emissions from a methanol-fueled ICEV are estimated at 0.13 grams/mile (0.081 grams/kilometer) (DeLuchi 1991); however, a higher efficiency FCV requires less fuel to be stored per mile traveled than an alcohol ICEV. As a result, per-mile evaporative emissions for the FCV are lower. This reduction is partially offset by the fact that a FCV will require a smaller fuel tank. Relative to a methanol ICEV, a smaller tank will mean that the FCV tank will have a higher surface-area-to-volume ratio. Because the rate of heat transfer to the fuel is proportional to the surface area of the tank, the higher surface-area-to-volume ratio of the smaller tank will increase fuel vaporization. However, because the fuel tank is not the only source of evaporative emissions or heat transfer, it is difficult to determine the impact that this increased surface-tovolume ratio will have. A FCV that is two times as efficient as a methanol ICEV can have a fuel tank that is half the volume and maintain an equivalent range. Assuming that the FCV fuel tank will be roughly rectangular in shape (as are those on current gasoline and methanol ICEVs) and the ratio of the three dimensions of that rectangular box remain fixed, a decrease in tank volume by a factor of two causes the surface-to-volume ratio to increase by $26 \%$. Thus, the rate of heat transfer to the fuel could increase as much as $26 \%$, causing higher rates of vaporization per gallon of fuel. In this analysis, we did not attempt to estimate the fraction of evaporative emissions coming from the fuel tank versus other sources (e.g., fuel lines and engine losses) and therefore have neglected any impacts from a smaller FCV fuel tank. Instead, evaporative emissions are assumed to be directly proportional to the quantity of fuel required per mile traveled.

On-board reformer emissions for the methanol FCV are estimated at 0.002 grams $/ \mathrm{mile}(\mathrm{gm} / \mathrm{mi})(0.0012$ $\mathrm{gm} / \mathrm{km}$ ) for NMOG, $0.001 \mathrm{gm} / \mathrm{mi}(0.0006 \mathrm{gm} / \mathrm{km})$ for $\mathrm{NO}_{\mathrm{x}}$, and $<2 \mathrm{ppm}(\mathrm{CO})$ (Patil 1991). CO emissions from the reformer are actually much higher, on the order of $200 \mathrm{ppm}$ to $3 \%$ (Seymour et al. 1992); however, because the PEM fuel cell is intolerant to even small concentrations of CO, preferential oxidation or methanation will be required to clean up the gas stream exiting the reformer. Therefore, overall CO emissions are expected to be less than $2 \mathrm{ppm}$.

\footnotetext{
32 The hydrogen FCV is also not carbon-neutral when considered over the entire fuel cycle. $\mathrm{CO}_{2}$ emissions from reforming
} natural gas off-board the vehicle to produce hydrogen are accounted for in the upstream stages of the hydrogen fuel cycle. 


\subsection{Results}

The following section reports the calculated benefits of FCV deployment in terms of national aggregate fuel savings, consumer economics, reductions in oil consumption and import, and emissions reductions. These estimates are based on the assumptions outlined in previous sections regarding market penetration, FCV efficiency, fuel costs, and emissions; however, in addition to the base results, we also present the results of a series of parametric studies. These studies were designed to test the sensitivity of the results to changes in key variables and are an important component of the overall analysis framework in that they facilitate a full understanding of the potential benefits estimated in this report.

\subsection{Fuel Savings}

\subsubsection{National Aggregate Savings}

The greater efficiency projected for FCVs versus the ICEV results in large savings in fuel expenditures to the vehicle user. These savings are entirely due to efficiency gains (less Btus or GJ required per mile or kilometer traveled), as the cost of fuels for the FCVs (on a Btu or GJ basis) are projected to exceed that of gasoline by a small margin throughout the period of analysis (see Figure 4). Natural gas is assumed to be the feedstock for both the methanol and hydrogen fuels used by FCVs. The higher distribution costs associated with handling a larger volume of methanol versus gasoline, reflecting methanol's lower energy density, is the main factor causing the fuel costs per unit of energy (MMBtu or GJ) of the FCV to be higher than those of the ICEV. Similarly, the higher costs of handling a gaseous fuel compared to a liquid causes delivered hydrogen costs to be relatively high. In the future, additional gains may be achievable if biofuels, photoconversion, or other renewable technologies are developed that provide a lower cost source of either methanol or hydrogen. Based on the results of this analysis, however, low fuel prices for the FCV are not a prerequisite to achieving substantial benefits, as the national aggregate savings calculated here are driven solely by the efficiency of the FCV.

Table 2. Present Value (in 1994) of Fuel Cost Savings from Light Duty FCVs Replacing Conventional ICEVs (billion $\$ 1991$ at $4.0 \%$ discount rate)

\begin{tabular}{|c|c|c|c|}
\hline & \multicolumn{3}{|c|}{ Market Penetration Case } \\
\hline & Sales by 2030 & 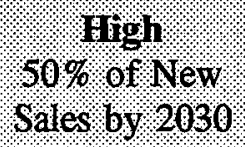 & $\begin{array}{l}12 \% \text { of } \\
\text { Sales by } 2030\end{array}$ \\
\hline 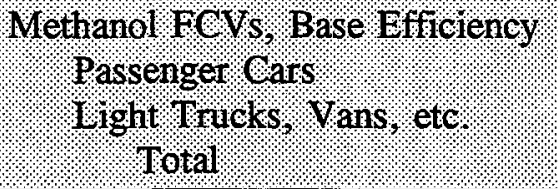 & $\$ 2,8$ & $\frac{\$ 33.9}{\$ 67.1}$ & $\frac{\$ 5}{\$ 1.9}$ \\
\hline 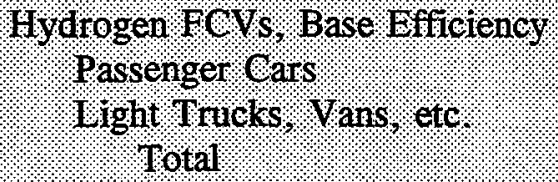 & $\begin{array}{l}\$ 16.6 \\
\$ 30.0 \\
\$ 46.5\end{array}$ & $\frac{\$ 26.2}{\$ 4.9}$ & $\frac{\$ 5}{\$ 10.4}$ \\
\hline
\end{tabular}


As shown in Table 2, the present value of fuel savings in 1994 are estimated to be $\$ 63.8$ billion in the base market penetration case for the methanol FCV and $\$ 46.5$ billion for the hydrogen FCV. The present value of savings in the high market penetration case are substantially greater ( $\$ 101.0 / \$ 74.1$ billion) and much lower in the low penetration case ( $\$ 17.6 / \$ 15.5$ billion). It should be noted that discounting to obtain present values tends to minimize the apparent importance of the savings in the later years, even at the low 4.0\% discount rate assumed (Lippiatt 1992).

\subsubsection{Consumer Economics}

The large savings in fuel expenditures projected in this study for light duty FCVs should make the FCV more attractive versus the conventional gasoline light duty ICEVs. If all other operating characteristics of the FCV (e.g., range, comfort, reliability, maintenance and insurance costs, taxes, and safety) are equal or equivalent to those of the gasoline ICEV, the fuel cost savings would permit a premium to be paid for the FCV. Currently, the fuel cell power system costs substantially more than the gasoline ICEV system. In the future, it is expected that the cost of fuel cell power systems (fuel cell stacks, reformers and fuel storage, batteries, electric drive systems, and related suspension and cooling systems) will be reduced substantially. While a preliminary study by General Motors indicates that electrochemical engine costs may be quite competitive in the long term (GM/Allison 1993), our study does not seek to estimate FCV purchase price directly because of the uncertainties involved. Instead, we use the potential fuel savings to estimate the size of an acceptable premium in purchase price, should one be required. The consumers' views at the time of purchase regarding the present value of fuel savings will influence the premium that they might be willing to pay for an FCV if there are no tax, environmental, or regulatory incentives (or the additional premium over and above any compensation from incentives).

One method of estimating the premium that might be acceptable to consumers is to discount the future savings on a vehicle to their present value at the time of purchase. For such purposes, a $10 \%$ real discount rate is approximately equal to a credit card variable interest rate for consumers or a business' minimum acceptable rate of return on new projects. A $15 \%$ real discount rate would include an additional "risk" factor to compensate for the uncertainties of the future savings versus the real premium paid at the time of purchase. ${ }^{33}$ The present values calculated for vehicles of three model years are shown in Table 3. The values for a particular case rise over time as efficiency improves and gasoline prices are projected to rise. ${ }^{34}$

33 The assumption is made implicitly that the initial purchaser expects that if he sells the vehicle before it is scrapped, the buyer of the used vehicle will place a similar value on fuel cost savings. The unknown value that will be placed on a newtechnology vehicle in the used car market adds to the risk factor.

34 For purposes of calculating these present values, the savings per vehicle mile were held constant for the portion of the vehicles' lives that extend beyond 2030. This was accomplished by holding the prices of fuels constant, including the natural gas and crude oil that are the feedstocks for methanol, hydrogen, and gasoline. This will understate the incentives to use FCVs if the price of crude oil rises relative to those of natural gas, biomass, or other renewable sources of hydrogen after 2030 . 
Table 3. Present Value of Fuel Cost Savings of New Fuel Cell Vehicles (base case penetration; base efficiency)

\begin{tabular}{|c|c|c|c|c|c|c|}
\hline Model Year & \multicolumn{2}{|c|}{2010} & \multicolumn{2}{|c|}{2020} & \multicolumn{2}{|c|}{2030} \\
\hline Discount Rate (real) & $10 \%$ & $15 \%$ & $10 \%$ & $15 \%$ & $10 \%$ & $15 \%$ \\
\hline \multirow{3}{*}{ Passenger cars : } & & & & & & \\
\hline & 81.910 & $\$ 1,500$ & $\$ 2,330$ & 81.830 & $\$ 2,450$ & $\$ 1,930$ \\
\hline & 51,530 & 81,190 & $\$ 2,020$ & $\$ 1.580$ & $\$ 2,150$ & $\$ 1.690$ \\
\hline \multicolumn{7}{|c|}{ Somnercial lyght Trueks } \\
\hline Methanol & $\$ 5,300$ & $\$ 4,050$ & $\$ 6,300$ & 84.820 & $\$ 6.590$ & $\$ 5,060$ \\
\hline Uy,orogen & 84,460 & $\$ 3,400$ & $\$ 5.610$ & $\$ 4,290$ & $\$ 5,910$ & 84,540 \\
\hline
\end{tabular}

The results shown in Table 3 suggest that if a consumer is seeking to offset any initial premium in purchase price with lowered operating costs over the life of the vehicle, $\$ 1,200-\$ 2,500$ might be the upper limit for passenger cars if there are no other incentives-taxation, regulation, emissions controls, rebates-to encourage its sale. Commercial light trucks, because they travel more miles per year and because the equivalent ICEV has a high fuel consumption, offer substantially greater savings per vehicle than passenger cars, and allowable premiums might be $\$ 3,400-\$ 6,600$. Since the present value of the savings is proportional to mileage driven, it is obvious that a vehicle user expecting to drive twice the average mileage could afford to pay twice the premium that the average user might be willing to pay. This applies equally to passenger cars and light trucks. From a policy point of view, the greatest national benefits can be derived by encouraging the use of a given number of vehicles in the highest mileage applications. ${ }^{35}$

\subsubsection{Reduced Oil Demand}

The reduction in demand for crude oil in the base penetration case would be 6 million barrels in 2010, 228 million barrels in 2020, and 876 million barrels in 2030, or a cumulative total of 6.5 billion barrels from 2000 through 2030. Crude oil demand would be reduced by 10.4 billion barrels in the high penetration case over the same period. In addition to the fuel cost savings, balance of payments pressures would also be lowered as a result of such reductions. ${ }^{36}$ If all the reduction in oil demand were of imported oil, import outlays in the base penetration case would be reduced by $\$ 0.2$ billion in 2010 , $\$ 8$ billion in 2020 , and $\$ 32$ billion in 2030 . The reductions would be nearly double that amount in the high

\footnotetext{
35 For example, $15 \%$ of light trucks are driven 20,000 miles $(32,180 \mathrm{~km})$ or more per year (Bureau of the Census 1990$)$.

36 At the same time, reduced transfers of money from the United States to oil-rich regions of the world will reduce the ability of these nations to purchase U.S.-made products in return.
} 
penetration case. The value of such a reduction in imports in those future years would depend upon the competitive position of the United States in world commodity and capital markets at that time.

\subsubsection{National Security Value}

The value in national security of reduced dependence on oil imports, particularly after 2010 when the diversity of source countries having crude oil available for export may diminish, is a matter of considerable debate and range of opinions. A figure of $\$ 4$ per barrel (equivalent to 10c/gallon, or 2.6 c/liter) has been suggested as an appropriate value, with other estimates being both higher and lower. ${ }^{37}$ Using the $\$ 4$ figure as a tentative value, and assuming all the reduction in demand would be of imports, the national security value of the reduction of crude imports in the base penetration case would be $\$ 7.5$ billion in present value terms. If only half of the oil demand reduction were of imported oil, the total security benefits would be half as large, or $\$ 3.7$ billion. ${ }^{38}$

\subsubsection{Parametric Studies}

We conducted parametric studies to identify the sensitivity of the results to changes in key variables. These include:

- $\quad$ FCV penetration rates

- $\quad$ FCV efficiency versus ICEVs

- $\quad$ crude oil prices and their impact on gasoline costs

- methanol and hydrogen costs

- alternative sources of methanol and hydrogen.

Figures 11 and 12 show the key results of parametric studies of several variables. In the case of methanol vehicles, the difference between achieving the high efficiency target proves to have a relatively small present value impact. However, the difference in the long term is much greater (i.e., without discounting to present value). Similarly, if we assume that the long-run fuel economy of the FCV is only twice that of the competing ICEV (rather than 2.5 times that of the ICEV as is assumed for the base case in 2020), the impact on the total benefits is fairly small.

As Figure 11 demonstrates, the future escalation of crude oil prices is a major variable affecting the total benefits, although prices were not assumed to change as a result of FCV penetration. The EIA projections of natural gas prices (EIA 1991) indicated that there would be very little variation of natural gas prices with higher or lower crude oil prices or other economic variables. The high and low gas cases produced

37 National security impacts from oil imports include the threat of supply disruption or manipulation as well as military expenditures to maintain access to Persian Gulf oil. A wide range of estimates have been proposed in the literature (CRS 1992; EMF 1982); this value is derived from the aforementioned OTT strategic planning activity.

38 The period of extremely low world oil prices in the mid-1980s resulted in little shut-in production (i.e., closures) for domestic producers. Given that the marginal operating costs are very low for domestic producers once a field is developed, one expects little reduction in domestic production as a result of the reduced demand calculated in this analysis. Sustained levels of lower demand and reduced prices will, however, likely impact the level of new exploration and, to a lesser degree, development expenditures. The impact on production would lag by several years. 
almost imperceptible differences in the final economics over the entire range. The lack of response of gas supply costs to changes in demand or to higher or lower crude oil prices may be reasonable, but the EIA projections do not provide an adequate test of the sensitivity of fuel savings to the cost of methanol; hence, a $20 \%$ range was analyzed that might reflect variations in conversion costs, efficiency, transportation and marketing costs, or other factors as well as variations in natural gas prices. A $20 \%$ higher methanol cost would offset one-fourth of the base case gains, and $20 \%$ lower costs would increase benefits by that same amount.

Little variation in the economics is attributable to the source of methanol, whether $50 \%$ domestic (base case assumption), $100 \%$ domestic natural gas source, all from biomass at DOE program target costs, or $20 \%$ higher biomass delivered cost. The uncertainties regarding future fuel costs are so great, and the differences among the estimated costs so relatively small, that selecting one technology/fuel combination at this point in time would be premature. Finally, Figure 11 shows that if we assume that the competing ICEV continues to improve in fuel economy beyond 2010, the benefits of a switch to FCVs increase as well. This is because we assume that changes to the ICEV that increase its efficiency will apply equally as well to FCVs (e.g., reduction in aerodynamic drag, low weight materials, and low resistance tires). Thus, the FCV continues to maintain its efficiency premium relative to the ICEV.

Finally, the benefits from the OTT Scenario, which combines an alternative assumption about FCV penetration and a slightly higher fuel economy projection, are nearly identical to our base case results. This is because the majority of the differences between the assumptions of this analysis and that of the OTT study occur in the later years of the analysis. As a result of discounting future savings, these longterm differences have a smaller impact on present value benefits.

The parametric studies for hydrogen vehicles produced similar results to those for methanol vehicles. Higher efficiency has a small present value impact, as in the case of methanol. However, since hydrogen prices are assumed to be higher than those of methanol, an increase in efficiency for the hydrogen FCV results in a greater increase in aggregate benefits (Figure 12) than for increases in the methanol FCV efficiency (Figure 11). As in the case of methanol, total benefits are sensitive to crude oil price assumptions and, to a lesser extent, the price of the fuel used by the FCV. Because of the uncertainty surrounding the future cost of hydrogen, we show the change in benefits for hydrogen costs $20 \%$ greater and $20 \%$ lower than assumed in the base case. In addition, the potential benefits associated with preliminary estimates of hydrogen costs from alternative production methods are also assessed, including: hydrogen from natural gas reformed at the service station (versus large-scale hydrogen conversion), biomass-derived hydrogen, and hydrogen produced via photoconversion on a distributed basis. 
In the base case, we have assumed that the hydrogen FCV will be $15 \%$ more efficient than the methanol FCV because the intermediate methanol-reforming step is removed. The "low efficiency premium" case shows the change in benefits if a hydrogen FCV is only $5 \%$ more efficient than the methanol FCV. Finally, Figure 12 shows that the combination of a high efficiency FCV (a $15 \%$ improvement over a highly efficient methanol FCV) and higher crude oil prices would provide the largest benefits, as expected.

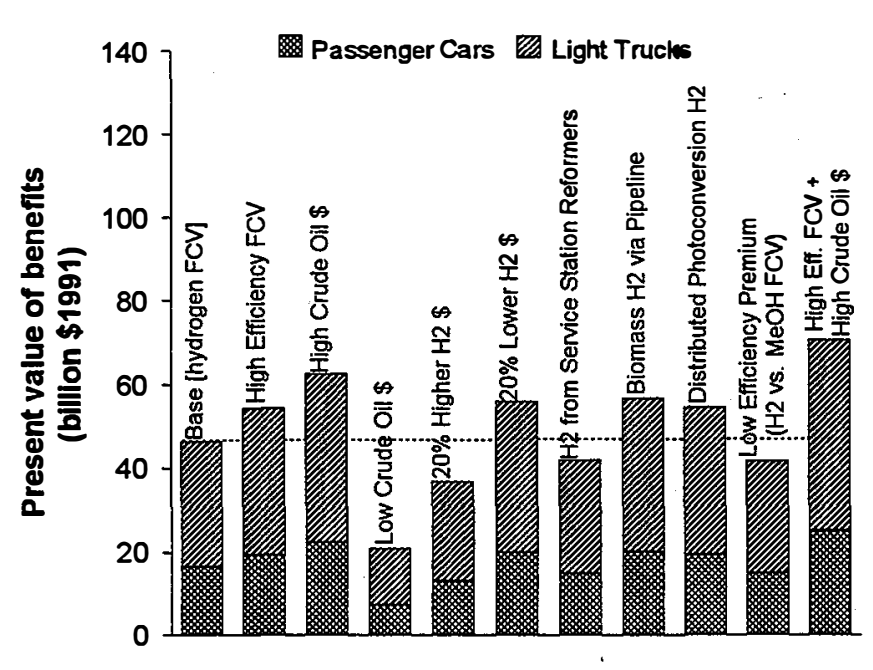

Figure 12. Results of the parametric studies for hydrogen fuel cell vehicles

\subsection{Emissions Reductions}

The use of FCVs operating on either methanol or hydrogen can result in significant emissions reductions relative to the operation of gasoline-powered ICEVs. Such reductions are achievable even when a total fuel cycle accounting of emissions, i.e. ,one that includes vehicular and upstream emissions (those from fuel production and distribution), is undertaken. Figures 13-16 display both the emissions from the vehicles themselves as well as the upstream emissions allocated on a per-mile basis for the ICEVs and FCVs.

Emissions from the end use of the vehicle dominate the total fuel cycle emissions (upstream plus vehicular) associated with the ICEVs, and two sets of emissions levels are considered in the analysis, corresponding to the Tier I standards of the 1990 CAAA (base) and the California LEV Program. Because the FCV has near-zero vehicular emissions, upstream emissions from producing and distributing methanol or hydrogen dominate the total fuel cycle emissions of the FCV scenarios. However, upstream emissions for the FCVs are still typically lower than those of the ICEV because FCVs use less fuel, and less upstream activities are therefore required to support each mile traveled by the vehicle.

The results shown in Figures 13-15 demonstrate that the implementation of the LEV program can result in large reductions in regulated emissions compared to the Tier I requirements of the CAAA. This is a result of two factors. First, the LEV emission standards are more stringent than the CAAA regulations. Second, we have assumed that the LEV program includes a "maximum" I/M program (versus the "enhanced" biennial program assumed for the base case) that will severely limit the rate of emissions deterioration over a vehicle's life and improve the rate of compliance with the applicable standards. 


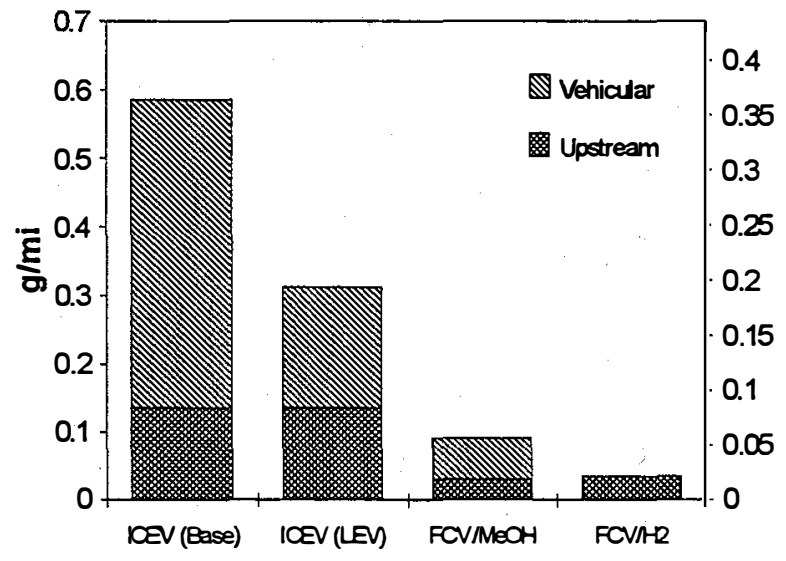

Figure 13: NMOG emissions from light duty vehicle use in 2020

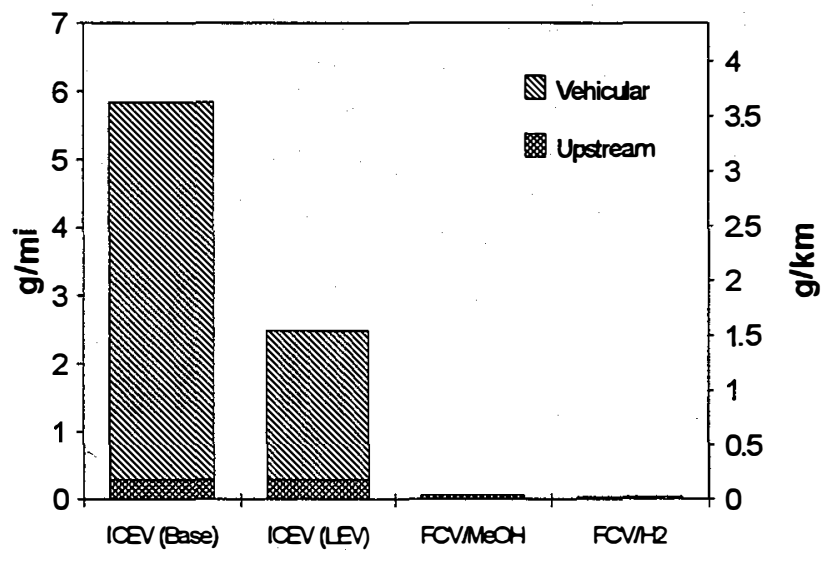

Figure 14. $\mathrm{CO}$ emissions from light duty vehicle use in 2020

Estimated emissions of NMOG for vehicles operating in 2020 are shown in Figure 13, demonstrating the large reductions achievable through the use of FCVs. Vehicular emissions include both those from the tailpipe as well as evaporative emissions during refueling, running, and resting. In the case of the gasoline ICEV, the majority (60\%-80\%) of the emissions come directly from the tailpipe. On the other hand, vehicular emissions of NMOG from the methanol FCV are primarily associated with the evaporation of the fuel stored on board the vehicle because the emissions from the on-board reformer are small. As expected, the hydrogen FCV has no vehicular emissions of NMOG, as there are no hydrocarbon fuels stored on board the vehicle.

Figure 14 demonstrates that even larger reductions in the per-mile emissions of $\mathrm{CO}$ are available from the use of FCV technology. This is because the hydrogen FCV has no CO emissions, and the methanol FCV generates extremely low $\mathrm{CO}$ emissions during fuel reforming. In addition, the upstream emissions associated with the production of methanol and hydrogen (as well as gasoline) are small.

In contrast to $\mathrm{CO}$ releases, upstream emissions of $\mathrm{NO}_{\mathrm{x}}$ are a significant portion of the total emissions from the methanol, hydrogen, and gasoline energy cycles (Figure 15). The production of all three fuels involves processes that operate at relatively high temperatures, resulting in large thermal $\mathrm{NO}_{\mathbf{x}}$ emissions.

In addition to the three regulated pollutants discussed above, $\mathrm{CO}_{2}$ emissions were estimated for all three energy cycles, as shown in Figure 16. There is no difference between the two ICEVs operating under the Tier I and LEV standards, since the regulations on which these two cases are based do not include $\mathrm{CO}_{2}$ emissions. The methanol FCV emits carbon dioxide at the tailpipe, since the on-board reforming of methanol to produce hydrogen will generate $\mathrm{CO}_{2}$ as a by-product. For the hydrogen $\mathrm{FCV}$, the $\mathrm{CO}_{2}$ emissions generated from hydrogen production are accounted for in the upstream portion of the bar, since these occur off-board the vehicle.

FCVs reduce $\mathrm{CO}_{2}$ emissions because they are more efficient, and (analogous to fuel-switching strategies being proposed for carbon emissions reductions in the utility sector) they use fuels that are derived from 


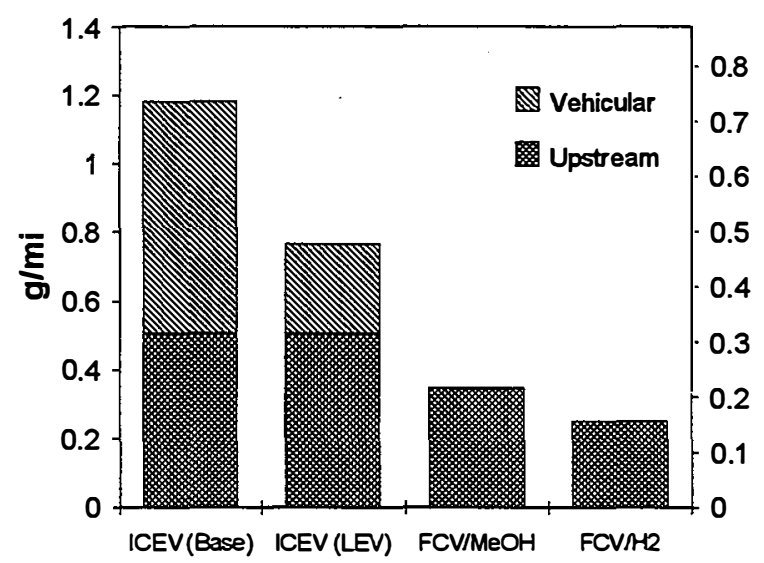

Figure 15. $\mathrm{NO}_{\mathrm{x}}$ emissions from light duty vehicle use in 2020

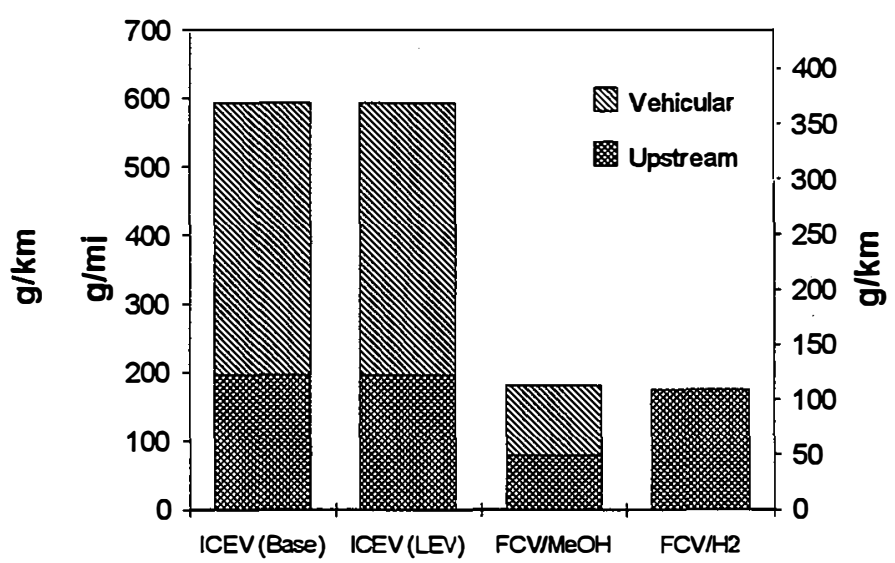

Figure 16. $\mathrm{CO}_{2}$ emissions from light duty vehicle use in 2020

natural gas rather than petroleum. Because of differences in the hydrogen-to-carbon ratio of natural gas and petroleum, natural gas releases roughly $31 \%$ less carbon per unit of energy available than does oil (Marland and Pippin 1990). Therefore, a fuel based on natural gas will have lower overall carbon emissions, all other factors being equal. In this analysis, only natural gas feedstocks are considered for methanol and hydrogen production; however, the use of renewable feedstocks, for which zero net carbon emissions may be achievable, ${ }^{39}$ would offer the potential to further reduce, if not altogether eliminate, $\mathrm{CO}_{2}$ emissions associated with transportation sector energy use. Such renewable pathways may also have lower emissions of the other key pollutants considered in this analysis, since the activities associated with, for example, photoconversion processes that produce hydrogen are relatively benign.

\subsubsection{Total Emissions Reductions}

Based on the differences in grams/mile emissions between ICEVs and FCVs, combined with the assumed FCV penetration rates, total quantities of avoided emissions are calculated to demonstrate the overall environmental benefits of FCVs. As Table 4 indicates, sizeable reductions of key pollutants are available from the use of FCVs. Depending on the pollutant and technology characterized, $70 \%-99 \%$ of the total fuel cycle emissions associated with ICEVs can be avoided by the use of FCVs over the period 20102030. Reductions of $\mathrm{CO}$ are the largest, since FCVs emit very small quantities of this pollutant over the total fuel cycle. On the other hand, the large upstream emissions of $\mathrm{NO}_{\mathrm{x}}$ in hydrogen and methanol production cause substantially smaller reductions in $\mathrm{NO}_{x}$ emissions from a switch to FCVs. These results highlight the importance of a total fuel cycle accounting of emissions: while the FCV nearly eliminates $\mathrm{NO}_{\mathrm{x}}$ emissions from the tailpipe, the total fuel cycle benefits are not as large as a result of including upstream emissions.

39

Minor carbon emissions can be associated with renewable energy technologies as a result of fossil fuel energy inputs to technology manufacturing, feedstock collection, and fuel distribution. 
As expected, Table 4 shows that the lower-emitting hydrogen FCV results in slightly larger benefits than the methanol FCV; however, this improvement is not overwhelming. Because the difference in emissions between ICEVs and FCVs is large, the small reduction in per-mile emissions from a FCV operating on hydrogen versus methanol does not affect the results significantly. In other words, a switch to either type of FCV is extremely beneficial, but the incremental environmental benefit associated with operating a FCV on hydrogen versus methanol is not substantial. ${ }^{40}$

\section{Table 4. Cumulative Emissions Reductions from the Use of Fuel Cell Vehicles for the Period 2010-2030}

\begin{tabular}{|c|c|c|c|c|}
\hline & \multicolumn{2}{|c|}{ 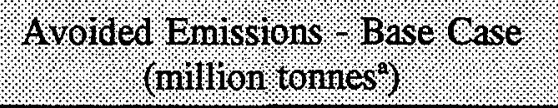 } & \multicolumn{2}{|c|}{ Erisissions Rediuetions. } \\
\hline & Methanol fov & Hydrogen frov & Methanol FOV & Hodrogen rOV \\
\hline NMOG & 32. & 3.5 & $86 \%$ & $95 \%$ \\
\hline $\mathrm{NO}$ & 5. 3 & S.8. & $73 \%$ & $81 \%$ \\
\hline co & 36.9 & 370 & $99 \%$ & $99 \%$ \\
\hline $\mathrm{CO}_{2}$ & 2,298 & 2,329 & $70 \%$ & $7 \%$ \\
\hline
\end{tabular}

The magnitude of the emission reduction numbers shown in Table 4 understates the value of these reductions to those regions where local air quality is particularly poor. Nearly one-half of the U.S. population resides in an area of ozone non-attainment, reflecting the large scale of the urban air pollution problem (OTA 1989). Reductions in emissions of NMOG and $\mathrm{NO}_{\mathbf{x}}$ will help abate ozone formation, and lower CO emissions will result in additional air quality benefits. Thus, the 45-46 million tonnes of criteria air pollutant emissions (i.e., NMOG, $\mathrm{CO}$, and $\mathrm{NO}_{x}$ ) avoided in the base FCV penetration case will carry important benefits, as the following section indicates. In addition, although not quantified in this report, FCVs will also help reduce emissions of other air pollutants of interest for local air quality, including air toxics, particulates, and sulfur oxides.

To place the economic and environmental benefits on an equal footing, the economic value of the avoided emissions is calculated using the following estimates of pollutant values ( $\$ 1991 /$ tonne): 3495 (NMOG), $3153\left(\mathrm{NO}_{\mathrm{x}}\right)$, and $342(\mathrm{CO}){ }^{41}$ Although there continues to be uncertainty over the role that carbon

\footnotetext{
40 This assumes that both methanol and hydrogen are derived from the same feedstock- natural gas. If we were to assume that one of the fuels were derived from an altemative source, such as renewable biomass or solar energy, then the difference in environmental benefits would be noteworthy.

41 Based on an assessment by EPA of the avoided cost values implied by the 1990 CAAA, as reported in DOE (1990). Original values are presented in $\$ 1990$ have been scaled for use in this analysis by the Gross Domestic Product deflator. In addition, the value for hydrocarbons (HC) reported in that document is assumed to be appropriate for valuing NMOG, the specific terminology used to describe hydrocarbon emissions in this report. The original values were (\$1990/ton): $\$ 3,050$ (HC), $\$ 2,750$ $\left(\mathrm{NO}_{\mathrm{x}}\right)$, and $\$ 300(\mathrm{CO})$. Because of the inherent uncertainty in these values, the parametric studies examined a wide range for
} 
emissions play in global climate change, we have also assessed the impact of assuming a monetary value for $\mathrm{CO}_{2}$. The results of the parametric studies demonstrate the impact of assuming a full range of values, from $\$ 0 /$ tonne $\left(\mathrm{CO}_{2}\right)$ to $\$ 61 /$ tonne $\left(\mathrm{CO}_{2}\right){ }^{42}$ and Figure 17 illustrates the benefits of emissions reductions for two cases: one in which $\mathrm{CO}_{2}$ reductions have no monetary value, and one in which the value is $\$ 16.5 /$ tonne $\left(\mathrm{CO}_{2}\right){ }^{43} \mathrm{As}$ the figure demonstrates, the cumulative benefits from reducing emissions increase substantially when a monetary value is placed on $\mathrm{CO}_{2}$ reductions. As in the case of the fuel savings analysis, benefits accrued in the future are scaled back to present value using a $4.0 \%$ discount rate (Lippiatt 1992). ${ }^{44}$

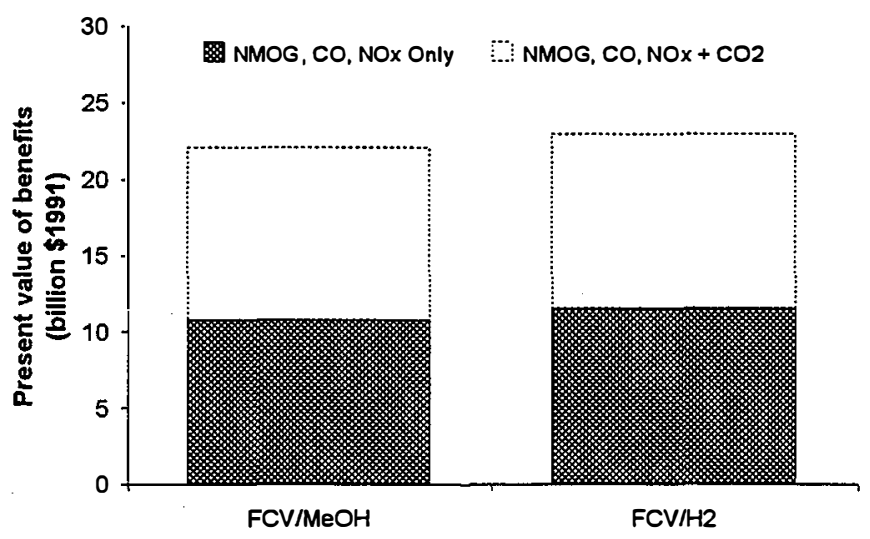

Figure 17. Cumulative environmental benefits (with and without $\mathrm{CO}_{2}$ valuation)

\subsubsection{Parametric Studies}

To study the sensitivity of our results to variations in key parameters, the environmental calculations were performed for variations in the following inputs:
- FCV penetration
- $\quad$ FCV efficiency
- $\quad$ tailpipe emissions regulations
- monetary value of avoided emissions.

The FCV penetration values, as well as the alternative FCV efficiency cases, are identical to those found in the fuel savings calculations. The variations in tailpipe emissions regulations were also discussed previously: the base case assumes that the Tier I standards of the 1990 CAAA apply and the excursion assumes that the California LEV Program standards are adopted nationwide. Finally, we have looked at

\footnotetext{
these estimates.

42 Equal to $\$ 0-\$ 55 /$ ton (English). This range is based on avoided cost estimates reported in the literature as well as proposed externalities costs for utility resource planning (Ledbetter and Ross 1990; Chemick and Caverhill 1989; EMF-12 1992; FERC 1992).

43 The value being used by the aforementioned OTT strategic planning activity.

44 There continues to be considerable disagreement in the environmental and economics communities as to the reasonableness of discounting future environmental benefits. It can be argued that, since environmental benefits have been monetized, future values can be scaled back to a present value like most other economic terms. The counter argument points out that doing so discounts future environmental quality, thereby violating the principles of intergenerational equity. We have continued to use the present value approach in the absence of a readily available alternative; however, this does not reflect a full acceptance of this approach to valuing future environmental quality.
} 
the impact of different assumptions regarding the monetary value of avoided emissions, as discussed in detail below.

The results of the parametric studies, shown in Figure 18 for the methanol $\mathrm{FCV},{ }^{45}$ demonstrate the expected increase in total benefits associated with a higher penetration of FCVs (and the similar reduction in the low penetration case). As can be seen, low FCV penetration results in a larger change in present value benefits than does the high case. This is a result of the delayed penetration associated with the low case and the important effect of discounting future benefits; because near-term impacts are valued at a higher rate than long-term ones, a delay in benefits causes a large reduction in their present value.

Assuming a high FCV efficiency appears to have little overall impact on the total benefits. Because emissions from FCVs are so low compared to ICEVs, changes in FCV emissions associated with an increased efficiency (and therefore lower upstream emissions) do not have a substantial impact on the overall reductions. The same reasoning applies to small incremental benefits of the OTT Scenario, which combines a slightly higher penetration rate (35\% in 2030$)$ with a much higher efficiency ( 3.18 times the ICEV fuel economy).

As Figure 18 indicates, changes in ICEV emissions do have an important impact, and total benefits are reduced by $56 \%$ if we assume that conventional vehicles will be subject to the more stringent standards of the LEV Program versus the federal Tier I standards. Policy shifts that result in tighter standards make the conventional vehicle more environmentally competitive, thereby reducing the environmental benefits associated with moving to an alternative. However, the cost of achieving these reductions using conventional vehicle technology may be substantial. Should expensive control equipment or fuel reformulations be required to meet the increased requirements of an LEV Program, the fuel savings and

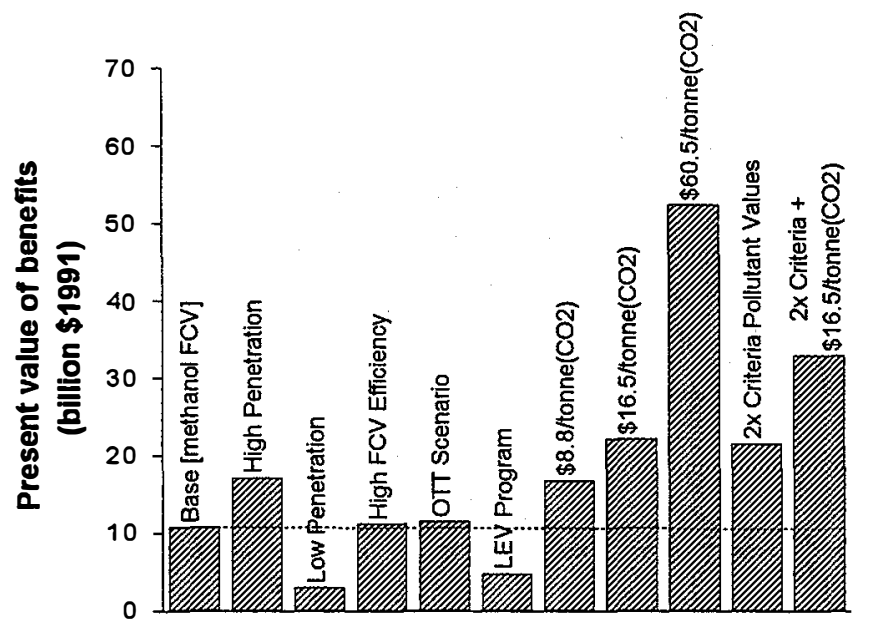

Figure 18. Parametric studies of emissions reductions consumer economics quantified in previous sections will look even more promising. Although not quantified as part of this analysis, the FCV could well be a more costeffective means of achieving emissions reductions in the long run than increasingly sophisticated (and expensive) adjustments to the conventional vehicle system.

Figure 18 indicates that the results of this analysis are particularly sensitive to assumptions made about the value of avoided emissions. Doubling the value assigned to reductions in criteria pollutants (NMOG, CO, and $\mathrm{NO}_{\mathbf{x}}$ ) doubles the benefits accrued, all else being held equal. The base values represent estimates of the avoided costs implied by meeting the requirements of the 1990 CAAA; however, achieving the larger

45 Although results of the parametric studies for the hydrogen FCV are not shown, they follow similar pattems. 
reductions required by the LEV Program will undoubtedly be more expensive, as additional control technologies and fuel reformulations may be required. Given the uncertainty in the public literature regarding control costs or the technical limits associated with different emissions standards, we have assessed the impact of doubling the base case value of avoided emissions as a means of encompassing these issues.

Because estimated reductions in $\mathrm{CO}_{2}$ emissions associated with $\mathrm{FCV}$ use are very large, we have considered a wide range of monetary values for avoided emissions. Figure 18 shows the impact of valuing $\mathrm{CO}_{2}$ reductions at $\$ 0 /$ tonne (included in the base case), $\$ 9 /$ tonne, $\$ 16.5 /$ tonne, and $\$ 61 /$ ton. This range is large, but representative of the current scientific and political uncertainty surrounding climate change. These values are based on avoided-cost estimates reported in the (relatively scant) literature on carbon reductions costs and taxes, as well as proposed externalities costs for utility resource planning (Ledbetter and Ross 1990; Chernick and Caverhill 1989; EMF-12 1992; FERC 1992). 


\subsection{Conclusions}

\subsection{Research Needs}

The analysis points to several areas where additional study can help refine the current work and provide a more complete accounting of the costs and benefits of a transition to FCVs. Some areas for further study include:

(1) The consumer economics analysis (Section 4.1.2) offers one approach to quantifying the size of an acceptable purchase price premium based on offsetting fuel cost savings over the vehicle's lifetime. Additional study of the potential costs and performance of FCVs will help determine their competitiveness relative to conventional vehicles and competing alternatives and identify the importance of future improvements to the success of FCVs in the marketplace.

(2) Further characterization of the light duty vehicle market, FCV costs and performance, and the future potential of conventional vehicles and competing alternatives will help refine the assumptions about market potential made in this analysis.

(3) Results of our preliminary analysis indicate that the use of fuels derived from renewable energy feedstocks could enhance future benefits of FCV use. The potential for renewable pathways to alternative fuel production should be explored in greater detail.

(4) The infrastructure requirements associated with fuel production and distribution, vehicle manufacturing, and vehicle servicing should be studied further to identify potential barriers to large-scale FCV and alternative fuel use as well as additional benefits that might be associated with these developments. For example, as Section 3.1.4.5 highlights, hydrogen distribution costs are relatively uncertain and could therefore be an area for further research.

(5) A detailed total fuel cycle analysis would improve the environmental benefits analysis by providing more detail than is currently available and permitting in-depth analysis of issues salient to the use of FCVs and the alternative fuels that they consume.

(6) As Section 4.2.1 describes, the costs associated with avoided emissions are highly uncertain, and further investigation might develop an improved set of values. For example, the costs associated with meeting increasingly stringent tailpipe emission standards should be reviewed to determine the full potential benefit of FCVs.

\subsection{Summary Results}

The analysis presented here demonstrates that the potential benefits from the deployment of FCVs, measured in terms of reduced consumer outlays for motor fuel and the value of reduced air emissions, are substantial. As Table 5 indicates, these benefits could total $\$ 74.6$ billion by 2030 for the methanol FCV and $\$ 58.0$ billion for the hydrogen FCV under the base case penetration scenario described in this report. The total benefits that can be accrued through the successful deployment of FCVs are substantially larger than the values given here. Specifically, the economic impacts associated with reduced petroleum prices, increased U.S. competitiveness (should the domestic automobile industry succeed in capturing the 
Table 5. Present Value ${ }^{a}$ of Fuel Savings and Emissions Reductions from the Deployment of Light Duty Fuel Cell Vehicles

(billion \$1991)

\begin{tabular}{|c|c|c|c|c|c|c|}
\hline & \multicolumn{2}{|c|}{ Base Penetration } & \multicolumn{2}{|c|}{ High Penetration } & \multicolumn{2}{|c|}{ Sow Peretraturt } \\
\hline & Hethanol: & Hydrogen & Hethonot: & Hodrogen & Methonol & Hodrogen \\
\hline guelsavings & 638 & 46. & 1010 & 74.1 & 116 & 15 \\
\hline Emissions Reductions & 108 & $1 \%$ & $11 \%$ & 183 & 30 & 32 \\
\hline $1014 \%$ & $14 \%$ & 580 & 1181 & $92 \%$ & $20 \% 6$ & 18. \\
\hline
\end{tabular}

a Cumulative benefits over the period 1994-2030, discounted at a real rate of $4.0 \%$.

- Excludes valuation of $\mathrm{CO}_{2}$ rechuctions.

FCV production market), job creation, and national security associated with reduced petroleum imports could be quite large.

Moreover, additional benefits can be realized from use of the fuel cell technology in other transportation systems (e.g., heavy duty trucks) as well as in other energy sectors (e.g., utility generation). In addition, research programs at the U.S. Department of Energy and elsewhere around the world are continuing to investigate the potential for renewable resources to serve as feedstocks for methanol or hydrogen production. The use of renewable energy, as our preliminary analyses indicates, may likely result in even larger energy, economic, and environmental benefits as a consequence of fully displacing the use of fossil fuel resources.

Assuming that FCVs operate solely on methanol and hydrogen derived from natural gas, this analysis demonstrates that the deployment of FCVs can result in substantial benefits to the nation and that increased market share results in proportionally greater savings. Our results also show that benefits from the deployment of FCVs increase sharply over time, thereby underscoring the importance of a long-term perspective in assessing fuel cells and other advanced transportation technologies. Finally, given the uncertainties of vehicle design, fuel supply costs, and future emissions standards, selecting a best vehicle/fuel combination based on the fuel savings and emissions reductions characterized here would be premature at this point in time. This analysis clearly demonstrates that the high efficiency and low emissions characteristics of fuel cell vehicles (regardless of the specific configuration), combined with their ability to operate on non-petroleum fuels, offers large potential benefits to the nation. 


\subsection{References}

Abrardo, J. (February 1994). Personal communication. Air Products and Chemicals, Inc.

Bureau of the Census (August 1990). Truck Inventory and Use Survey, 1987 Census of Transportation, TC87-T-52. Bureau of the Census, U. S. Department of Commerce. Washington, DC.

Calvert, J.G.; Heywood, J.B.; Sawyer, R.F.; Seinfeld, J.H. (July 2, 1993). "Achieving Acceptable Air Quality: Some Reflections on Controlling Vehicle Emissions." Science; Vol. 261, pp. 37-45.

Chernick, P.; Caverhill, E. (December 1989). The Valuation of Externalities from Energy Production, Delivery, and Use. Boston, MA: PLC, Incorporated.

Congressional Research Service (CRS) (June 1992). The External Costs of Oil Used in Transportation. 92-574 ENR. The Library of Congress.

Davis, S.; Strang, S. (March 1993). Transportation Energy Data Book: Edition 13. ORNL-6743. Prepared for Office of Transportation Technologies, U.S. Department of Energy.

DeLuchi, M.A. (1991). Emissions of Greenhouse Gases from the Use of Transportation Fuels and Electricity. ANL/ESD/TM-22, Vol. 1. Argonne, IL: Argonne National Laboratory.

DeLuchi, M.A.; Wang, Q; Greene, D.L (June 1992). Motor Vehicle Fuel Economy, the Forgotten HC Control Strategy? ORNL-6715. Prepared by Oak Ridge National Laboratory for the U.S. Department of Energy.

E.A. Mueller (1990). Emissions from Methanol Production. Prepared for U.S. Department of Energy, Office of Environmental Analysis.

Energy Information Administration (EIA) (January 1993). Annual Energy Outlook 1993 with Projections to 2010. DOE/EIA-0383(93).

Energy Modeling Forum 6 (EMF 6) (February 1982). World Oil. Stanford, CA: Stanford University.

Energy Modeling Forum 12 (EMF 12) (January 1992). Preliminary results. Palo Alto, CA: Stanford University.

Federal Energy Regulatory Commission (FERC) (December 1992). Report on Section 808: Renewable Energy and Energy Conservation Incentives of the Clean Air Act Amendments of 1990. Washington, DC.

Gas Research Institute (GRI) (1992). Baseline Projection Data Book, 1992 Edition Volume II. pp. 489, 494, 502, 556.

Gas Research Institute (GRI) (1993). '93 Policy Implications of the GRI Baseline Projection of U.S. Energy Supply and Demand to 2010. Washington, DC: Gas Research Institute.

Gates, M. (January 17, 1994). "'Clean Car' Group Aims for 80-mpg Car." Automotive News; p. 18. 
General Motors; Allison Gas Turbine Division (November 1993). Research and Development of ProtonExchange Membrane (PEM) Fuel Cell System for Transportation Applications: Initial Conceptual Design Report. EDR 16194. Prepared for the Office of Transportation Technologies, U.S. Department of Energy. Indianapolis, IN: General Motors Corporation.

German, J. (June 1993). "Actual Driving Behavior: Implications for In-Use Mobile Source Emissions." Presented at First Annual World Car 2001 Conference. University of California, Riverside, June 20-24, 1993.

Hudson, D.V., Jr. (April 1988). Analysis of Recent Long-Range Forecasts of Natural Gas Supply and Demand and Field Prices for Gas. SERI/MR-360-3327. Golden, CO: National Renewable Energy Laboratory.

Hudson, D.V., Jr. (April 1989). Analysis of the Outlook for Oil Supplies and Prices. SERI/MR-160-3564. Golden, CO: National Renewable Energy Laboratory.

International Fuel Cells (IFC) (August 1986). The PC25 Fuel Cell Power Plant. Technical specifications. South Windsor, CT: International Fuel Cells.

Kunz, R.G.; Smith, D.D.; Patel, N.M.; Thompson, G.P.; Patrick, G.S. (March 1992). "Control NO from Gas-Fired Hydrogen Reformer Furnaces." AM-92-56. National Petroleum Refiners Association Annual Meeting, 1992. March 22-24, 1992. New Orleans, LA.

Ledbetter, M.; Ross, M. (March 1990). "Supply Curves of Conserved Energy from Automobiles, " Paper prepared for Lawrence Berkeley Laboratory, Applied Science Division. Berkeley, CA.

Lippiatt, B. (October 1992). Energy Prices and Discount Factors for Life-Cycle Cost Analysis 1993: Annual Supplement to NIST Handbook 135 and NBS Special Publication 709. NISTIR 85-3273-7. Prepared by the U.S. Department of Commerce for the U.S. Department of Energy, Federal Energy Management Program.

Maples, J. (May 1993). "The Light Duty Vehicle MPG GAP: Its Size Today and Potential Impacts in the Future." Presented at SAE Government/Industry Meeting. Washington, DC.

Marland, G.; Pippin, A. (1990). "United States Emissions of Carbon Dioxide to the Earth's Atmosphere by Economic Activity." Energy Systems and Policy (14:4).

Miaou, S. (August 1990). Study of Vehicle Scrappage Rates. Oak Ridge, TN: Oak Ridge National Laboratory.

National Hydrogen Association (NHA) (n.d.). The Hydrogen Technology Assessment: Opportunities for Industry and Research, Phase I. Prepared for the National Aeronautics and Space Administration.

Office of Transportation Technologies (OTT) (1994). National Program Plan for Fuel Cells in Transportation: Technical Plan. (Draft). U.S. Department of Energy. 
Ogden, J.; Nitsch, J. (1992). "Solar Hydrogen." Fuels and Electricity from Renewable Sources of Energy. Williams et al. (eds.). Washington, DC: Island Press. Table 10, pp. 978-979.

Patil, P.G. (October 1991). "Fuel Cell Systems R\&D Program Overview." Proceedings of the Annual Automotive Technology Development Contractors' Coordination Meeting 1991. October 28-31. Dearborn, MI.

Seymour, C.M.; Belsey, O.A.; Dams, R.A.J; Moore, S.C. (December 1992). "The Development of a Proton Exchange Membrane Fuel Cell Power System." 1992 Fuel Cell Seminar: Program and Abstracts. November 29-December 2, 1992. Tucson, Arizona; pp.446-450.

Stedman, D.H., et al. (1991). On-Road Carbon Monoxide and Hydrocarbon Remote Sensing in the Chicage Area: Final Report. ILENR/RE-AQ-91/14. Springfield, IL: Illinois Department of Energy and Natural Resources.

Stedman, D.H.; Bishop, G.; Peterson, J.E.; Guenther, P.L. (1991). On-Road CO Remote Sensing in the Los Angeles Basin: Final Report. Sacramento, CA: California Air Resources Board.

U.S. Congress, Office of Technology Assessment (OTA) (July 1989). Catching Our Breath: Next Steps for Reducing Urban Ozone. OTA-O-412. Washington, DC: U.S. Government Printing Office.

U.S. Department of Energy (DOE) (November 1989). Assessment of Costs and Benefits of Flexible and Alternate Fuel Use in the U.S. Transportation Sector, Technical Report Three: Methanol Production and Transportation Costs. DOE/PE-0093. Office of Policy, Planning, and Analysis, U.S. Department of Energy.

U.S. Department of Energy (DOE) (December 1990). Benefits and Costs for an Enhanced Transportation R\&D Funding Level. (Draft). Office of Transportation Technologies, U.S. Department of Energy.

U.S. Environmental Protection Agency (EPA) (October 1992). National Air Pollutant Emission Estimates 1900-1991. EPA-454/R-92-013.

U.S. Environmental Protection Agency (EPA) (March 1993). Documentation for the MOBILE5a. Chapter 2 "Mobile5 Inputs."

U.S. Environmental Protection Agency (EPA)(July 1993). Compilation of Air Pollution Emission Factors, Volume I: Stationary Point and Area Sources - Supplement F. PB86-124906. 


\section{Appendix Conversion Factors}

Table A-1. English Units to SI Units

\begin{tabular}{|c|}
\hline Inile $=1.609 \mathrm{~km}$ \\
\hline $16=0454 \% g$ \\
\hline tron $($ short) $=0.907$ tonine \\
\hline 1 gallon $=3785$ niter \\
\hline loarrel $(1 \mathrm{~S})=1589701 \mathrm{lite}$ \\
\hline $1 \mathrm{Bra}=1055.056$ /oule \\
\hline
\end{tabular}

Table A-2. Conversion of Common Units

\begin{tabular}{|c|}
\hline $1 \% M M B r i=0.948 \% \mathrm{GJ}$ \\
\hline 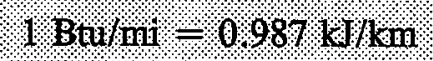 \\
\hline $4 \mathrm{npph}=1.609 \mathrm{kph}$ \\
\hline $1 \mathrm{npg}=0.425 / \mathrm{lan} /$ Hiter. \\
\hline $1 . \mathrm{g} / \mathrm{min}=1.6 .622 \mathrm{~g} / \mathrm{Kr}$ \\
\hline l. $\$$ t. \\
\hline
\end{tabular}




\begin{tabular}{|c|c|c|c|}
\hline $\begin{array}{l}\text { Document Control } \\
\text { Page }\end{array}$ & $\begin{array}{l}\text { 1. NREL Report No. } \\
\text { NREL-TP-463-6157 }\end{array}$ & $\begin{array}{l}\text { 2. NTIS Accession No. } \\
\text { DE94006909 }\end{array}$ & 3. Recipient's Accession No. \\
\hline \multirow{2}{*}{\multicolumn{3}{|c|}{$\begin{array}{l}\text { 4. Title and Subtitle } \\
\text { Fuel Savings and Emissions Reductions from Light Duty Fuel Cell } \\
\text { Vehicles }\end{array}$}} & $\begin{array}{l}\text { 5. Publication Date } \\
\text { April } 1994\end{array}$ \\
\hline & & & 6. \\
\hline \multicolumn{3}{|c|}{$\begin{array}{l}\text { 7. Author(s) } \\
\text { J. Mark, J. Ohi, and D. Hudson }\end{array}$} & 8. Performing Organization Rept. No. \\
\hline \multirow{2}{*}{\multicolumn{3}{|c|}{$\begin{array}{l}\text { 9. Performing Organization Name and Address } \\
\text { National Renewable Energy Laboratory } \\
1617 \text { Cole Boulevard } \\
\text { Golden, Colorado } 80401-3393\end{array}$}} & $\begin{array}{l}\text { 10. Project/Task/Work Unit No. } \\
\text { AS165440 }\end{array}$ \\
\hline & & & $\begin{array}{l}\text { 11. Contract (C) or Grant (G) No. } \\
\text { (C) } \\
\text { (G) }\end{array}$ \\
\hline \multirow{2}{*}{\multicolumn{3}{|c|}{ 12. Sponsoring Organization Name and Address }} & $\begin{array}{l}\text { 13. Type of Report \& Period Covered } \\
\text { Technical report }\end{array}$ \\
\hline & & & 14. \\
\hline \multicolumn{4}{|c|}{ 15. Supplementary Notes } \\
\hline \multicolumn{4}{|c|}{$\begin{array}{l}\text { 16. Abstract (Limit: } 200 \text { words) } \\
\text { Fuel cell vehicles (FCVs) operate efficiently, emit few pollutants, and run on nonpetroleum fuels. Because of } \\
\text { these characteristics, the large-scale deployment of FCVs has the potential to lessen U.S. dependence on foreign } \\
\text { oil and improve air quality. This study characterizes the benefits of large-scale FCV deployment in the light duty } \\
\text { vehicle market. Specifically, the study assesses the potential fuel savings and emissions reductions resulting from } \\
\text { large-scale use of these FCVs and identifies the key parameters that affect the scope of the benefits from FCV } \\
\text { use. The analysis scenario assumes that FCVs will compete with gasoline-powered light trucks and cars in the } \\
\text { new vehicle market for replacement of retired vehicles and will compete for growth in the total market. Analysts } \\
\text { concluded that the potential benefits from FCVs, measured in terms of consumer outlays for motor fuel and the } \\
\text { value of reduced air emissions, are substantial. }\end{array}$} \\
\hline \multicolumn{4}{|c|}{$\begin{array}{l}\text { 17. Document Analysis } \\
\text { a. Descriptors } \\
\text { fuel cell vehicles; light duty vehicles; fuel cells; fuel savings; emissions reductions } \\
\text { b. Identifiers/Open-Ended Terms }\end{array}$} \\
\hline \multirow{2}{*}{\multicolumn{2}{|c|}{$\begin{array}{l}\text { 18. Availability Statement } \\
\text { National Technical Information Service } \\
\text { U.S. Department of Commerce } \\
5285 \text { Port Royal Road } \\
\text { Springfield, VA } 22161\end{array}$}} & & $\begin{array}{l}\text { 19. No. of Pages } \\
56\end{array}$ \\
\hline & & & $\begin{array}{l}\text { 20. Price } \\
\text { A04 }\end{array}$ \\
\hline
\end{tabular}

Form No. 0069E (6-30-87) 